Portland State University

PDXScholar

Winter 3-15-2016

\title{
The Kazaks of Istanbul: A Case of Social Cohesion, Economic Breakdown and the Search for a Moral Economy
}

Daniel Marc Auger

Portland State University

Follow this and additional works at: https://pdxscholar.library.pdx.edu/open_access_etds

Part of the Civic and Community Engagement Commons, Other International and Area Studies Commons, and the Urban Studies Commons

Let us know how access to this document benefits you.

\section{Recommended Citation}

Auger, Daniel Marc, "The Kazaks of Istanbul: A Case of Social Cohesion, Economic Breakdown and the Search for a Moral Economy" (2016). Dissertations and Theses. Paper 2751.

https://doi.org/10.15760/etd.2752

This Thesis is brought to you for free and open access. It has been accepted for inclusion in Dissertations and Theses by an authorized administrator of PDXScholar. Please contact us if we can make this document more accessible: pdxscholar@pdx.edu. 
The Kazaks of Istanbul: A Case of Social Cohesion, Economic Breakdown and the Search for a Moral Economy

by

Daniel Marc Auger

A thesis submitted in partial fulfillment of the requirements for the degree of

Masters of Urban Studies in Urban Studies

Thesis Committee:

Gerry Sussman

Karen Gibson

Birol Yeşilada

Portland State University

2016 
(C) 2016 Daniel Marc Auger 


\begin{abstract}
This research is focused on understanding the ways in which the community orientation of the Kazak ethnic community in Istanbul, Turkey have contributed to their economic success which in turn encourages strong community, and the nature of their communitybased support networks for providing material and cultural support. It examines the role of social capital and cohesion in maintaining the community with its positive implications for the continued building of wealth or sourcing of funding on a community level. The theoretical concepts relevant to this project are based on the ideas that the shared values of a community are a positive force that allow communities to achieve common goals and is particularly important in the context of an economy that favors cheap labor and a highly mobile workforce, both factors that negatively affect the asset building and placebased rootedness that communities require for their stability. Key community entrepreneurs and leaders were the main sources of information for this research. The findings of this thesis suggest that it is a combination of factors such as the failure of the community to maintain its stable economic position through unfortunate business practices and choices coupled with external market forces that slowed this community economic development and disabled its continued growth.
\end{abstract}




\section{Acknowledgements}

I would like to thank the many people who helped make this work possible in particular the Kazak community members who dedicated time to speaking with me and sharing insights into their history and community. I would also like to thank my advisor and committee members who provided a great deal of thoughtful feedback and guidance that went into the shaping of this work. 


\section{Table of Contents}

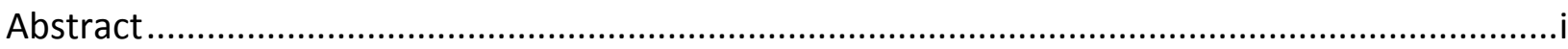

Acknowledgements.............................................................................................................

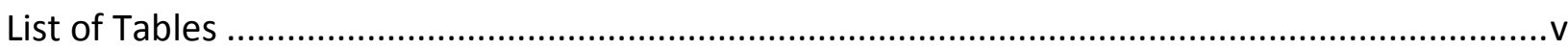

Chapter I. Introduction: The Survival of Ethnic Communities ................................................... 1

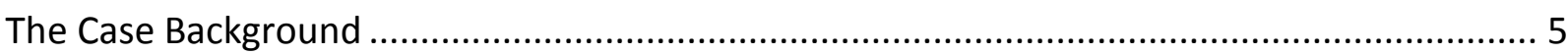

Chapter II. The Literature and Methodological Approach...................................................... 12

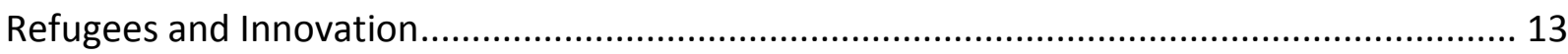

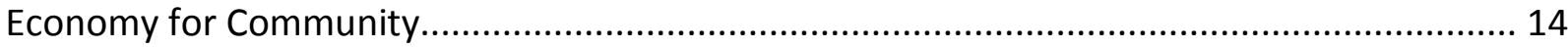

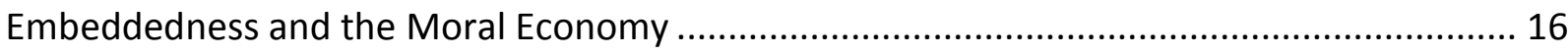

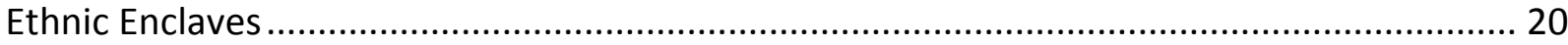

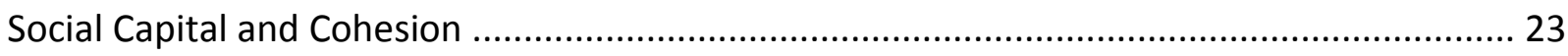

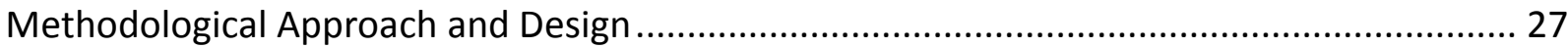

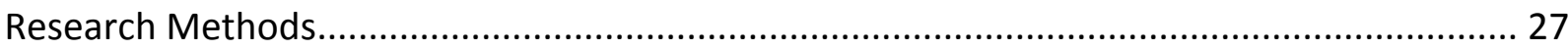

Chapter III. Background: The History of the Kazaks of Istanbul ................................................ 40

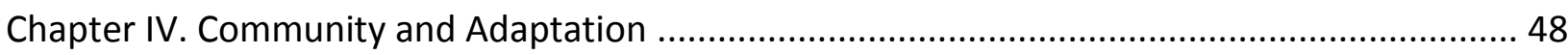

Community Among the Kazaks and Positioning in the Modern Economy ............................... 48

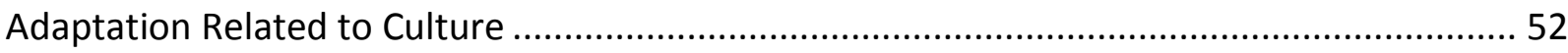

Embeddedness and the Moral Economy Among the Kazaks............................................... 58

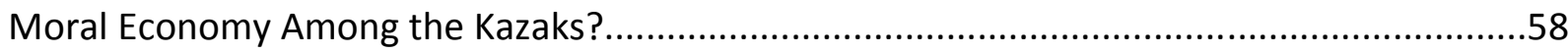

Chapter V. The Ethnic Enclave in the Zeytinburnu Kazak Context ............................................. 67

Economic Development and Social Aspects of the Enclave Economy......................................67

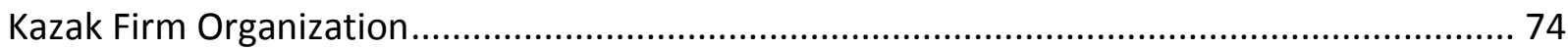

Chapter VI. Social Capital and Cohesion in Zeytinburnu .......................................................... 76

The Nature of Social Capital and Cohesion in the Kazak Community....................................... 76

The Kazak Turk Foundation and its Role in Fostering Social Capital....................................... 81

The Position of Education in the Community and its Relation to Social Capital ....................... 84 


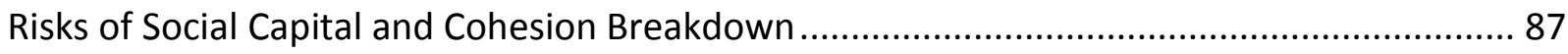

Missed Opportunities for Enhancing Social Capital ....................................................... 88

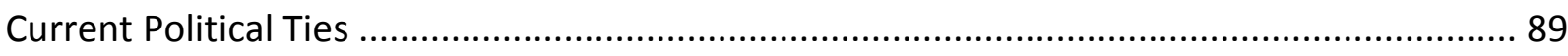

The Space Issue for Cultural Reproduction and Cohesion .............................................. 90

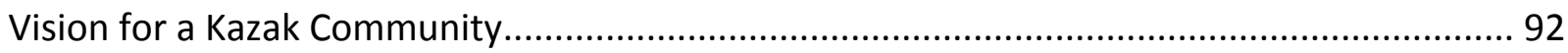

Connectedness as an Obstacle for Advancement.......................................................... 94

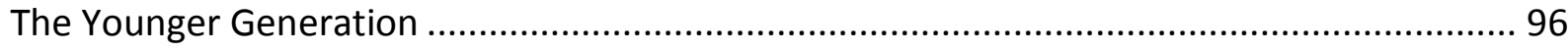

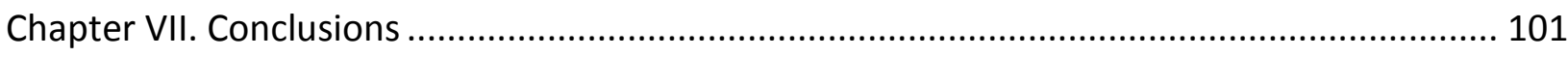

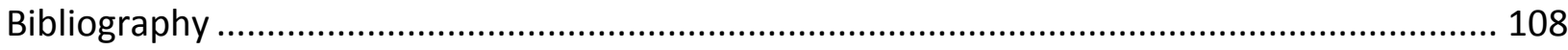

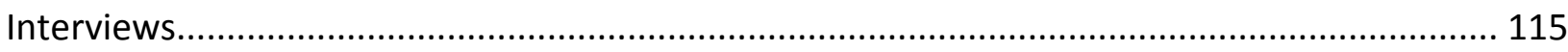




\section{List of Tables}

Table 1: Marriage types

. $.7 \& 77$

Table 2: Frequency of visits with fellow countrymen..................................................... \& \& 78

Table 3: Requirements for success in urban living..................................................... \& 80

Table 4: Education levels..................................................................................................

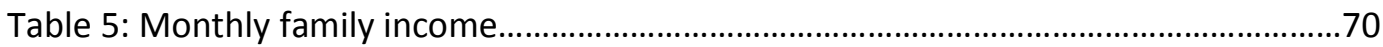

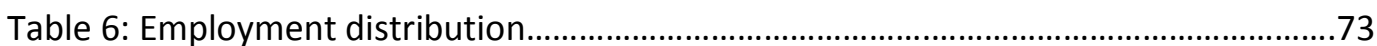

Table 7: Marriage partner qualities according to education level.......................................86 


\section{Chapter I. Introduction: The Survival of Ethnic Community Economies}

The whirr of sewing machines could be heard humming diligently from the leather workshops in the lively Zeytinburnu neighborhood of Istanbul, Turkey. The noxious smell of the area's old Ottoman era leather tanneries, zoned just outside the Byzantine walls, was no more but the neighborhood's relationship to the industry continued on. Communities of Greeks, who moved out to this empty, undeveloped land from the city of Constantinople when it was taken by the Ottomans in the mid- $15^{\text {th }}$ century, Armenians and Jewish residents who lived here are mostly gone as a result of $20^{\text {th }}$ century pogroms and a hostile climate to non-Muslim minorities. The place is now a working class neighborhood known for its masculine edge and as a destination neighborhood for migrants from the Anatolian countryside beginning in the 1950s.

One such group of migrants who added their unique way of life and economic contributions to the neighborhood was a tribe of Kazaks who brought with them a very strong sense of cohesion among its individual members. Originating from a nomadic lifestyle in the pastures of western China, the Kazaks eventually settled in the Zeytinburnu neighborhood of Istanbul, Turkey after leaving their homeland in the wake of political turmoil. Leather working know-how from a pastoral lifestyle, economic fortitude and a determination for independence were characteristics that assisted them in collective economic achievements. In fact, their history of economic independence and economy based on moral principles of socially-based economic relationships were significant factors for the continued cohesion of the community and provided the community with strength for collective economic action. 
The formation of the Kazak ethnic enclave in Istanbul developed out of a gradual migration of Kazak community members with earlier migrants setting the foundation for passing on information and connections for housing to the rest of the rural communities. Many more began moving to Istanbul as it became beneficial for lowering the transportation costs of materials coming from Istanbul to provincial centers near Kazak settlements in Sahlili and Manisa in the vicinity around the city of Izmir. Their particular skills turned out to be valuable for filling abandoned niches in the local economy and creating new ones as well as for enhancing economic diversity as was the case in Istanbul's leather industry at the time with the leaving of the Greeks and Jews.

At a crucial point, the community, garnering little economic benefit from traditional animal husbandry, began plying their leather working skills and engaging collectively in producing leather garments from industry scraps and the industry became or rather was born of a community affair driven by familial lines and labor pools that were family-based. These relationships were the organizing force for labor which drove their economy. This economy, in turn, became a force for the maintenance of the group's cohesion as a focal point for collective organization for a time.

Traditional bonds that maintain and strengthen cohesion within such groups can play an essential role in fostering developing economies - bringing increased wealth and vitality to communities, neighborhoods and secondary local beneficiaries that are outside the immediate in-group. The immigrant enclave is an important locus for such activity and is defined not only by its spatial concentration, which is a common pattern among all immigrant groups, but also characterized by the presence of ethnic firms that employ significant numbers of workers from the same ethnic group (Portes and Jensen, 1987). 
The social capital of group members may have benefits for the entire community. As observed in the Xinjiang Kazak community in Istanbul from the 1960s to the present, economic status improved through the collective employment of traditional skills into a single coordinated industry. Status further improved with urbanization while community cohesion was maintained through traditional lineage and social modes (Svanberg, 1989). The intentional maintenance of a segregated community involved notions of group separateness and superiority to the Turkish community, as well as the importance of endogamous lineage patterns in the culture of the Istanbul Kazaks (Svanberg, 1989). The combination of "traditionally" based values and skills conjoins with modes of adaptation to urbanization, seen as an important aspect of modernizing, to produce economic prosperity in this particular case. Favorable conditions led to Turkey as the location choice for the Kazak community in the early 1950s. In Turkey, the preference for immigration favored immigrants and refugees of Turkic descent based on pan-Turkist and nationalist ideology and the idea that all Turks and Turkic peoples constituted a 'super family.' The Turkish Settlement Law of 1934 stipulated that those of Turkish race or connected to Turkish culture and who spoke Turkish, and presumably related languages, were specified as those permitted to immigrate. For the first time, the national character of the Turkish population became a significant aspect of state security.

It was under these premises that the Kazak refugees, one of the multitudes of ethno-linguistic groups of Turkic peoples of the eastern Kipchak language group and in the case of Kazakistan, comprising an entire nation, were allowed to immigrate to Turkey and furnished with low-interest loans with favorable payment terms as well as language instruction and skill development programs provided by the Turkish state. Seen as a 
favorable group because of their Turkic origins and language, the political Pan-Turkist motivations of the Turkish state saw the Kazaks as a means to increasing the "Turkishness" capital in Turkey. What this means for the community itself, however, is perhaps of greater significance in terms of the creation of a supportive environment with material assistance in establishing some basic assets.

At some point in the Kazak's history in Turkey, the loop that linked economy to social relations was broken and slightly new forms of organization and orientation to the economy began to develop. The purpose of this paper is to explore the nature of the community economy of the Kazaks in light of this development. It is interested in determining the state of social capital within the community as it relates to the relation the community has to its business community and the relation community members have to one another. Social capital is frequently touted as an asset useful for furthering economic goals. The successful maintenance of healthy cohesion while engaging in economic activity that is community-based in nature and encourages the healthy existence of the community is the ideal vision that this research is founded in. The existence of a kind of moral economy or at least the remnants of a historical community economy that operated with a moral character is inseparable from the discussion of community for economy and is of primary interest to the topic of the Kazak community. This is significant to this research because most attempts at the creation and implementation of social welfare programs are essentially attempts to replace ones that existed through social relations prior to the market orientation of the world economy.This research is focused on understanding the ways in which the strong community factors of the Kazak ethnic community in Istanbul have contributed to their initial economic 
success and the nature of their community-based support networks for providing material and cultural support. It will examine the failings of the community in maintaining its relatively powerful economic position, the external and internal forces at work to slow this development and the community reactions to these changes. It is also interested in the role of social capital and cohesion in maintaining the community which may theoretically have positive implications for the continued building of wealth or sourcing of funding on a community level for the assistance of less well-off members. The working question for this paper is how has the idea of an economy for community played out in the Kazak community of Istanbul and why has this ultimately been a successful or a failed case? To answer this question this research looks at social cohesion and social capital dynamics a locus for understanding the quality of the Kazak economy. The underlying premise in this case is that cohesion is the underlying foundation of an economy that works for the community.

\section{The Case Background}

This exploratory study is looking at the Kazak community as a particular case for the preceding question. As a community uprooted with its social fabric mostly intact its interest for research lies in how this particular social fabric has fared when transplanted into an urban market economy from its traditional pastoral nomadic one. In effect, the new expressions of the community's social organization emerging from this transplantation, its translation into new forms of economic activity, and the merits of such social organization in creating material benefit for the whole community is of keen interest to this researcher. The Kazaks, residing in the former leather works Jewish and 
Greek neighborhood of Zeytinburnu today amidst a myriad of other Central Asian groups such as Uyghurs, Mongolians, Kyrgyz, Turkmen, Uzbeks and Afghans, groups which did not come as whole, intact communities and who fared less well economically, created a specific niche for themselves and used community resources to achieve a measure of success in establishing their community-based firms. The Kazak population of Zeytinburnu is about 12,000 individuals. Many adults still identify according to their original clan lineage and can explain their ancestral tree based on patriarchal descendancy. The core of the family is nuclear with extended family assuming fluid roles in child rearing. At times a child may be reared by his or her grandparents, an aunt and uncle or an older cousin even when the parents are still living and residing close by at times even just a block away (Abdülselam Malkoç, Interviews). The community is traditionally Sunni Muslim. Women assume traditional roles but also study, work and own businesses.

Kazak marriages are major community events and involve the extended family and friends as well as other associates. The majority of marriages are based on the choice sometimes with parent approval (28.5\%) sometimes without family interference (16.3\%) (Çiğdem, p. 63) based on data from this 2002 study. 


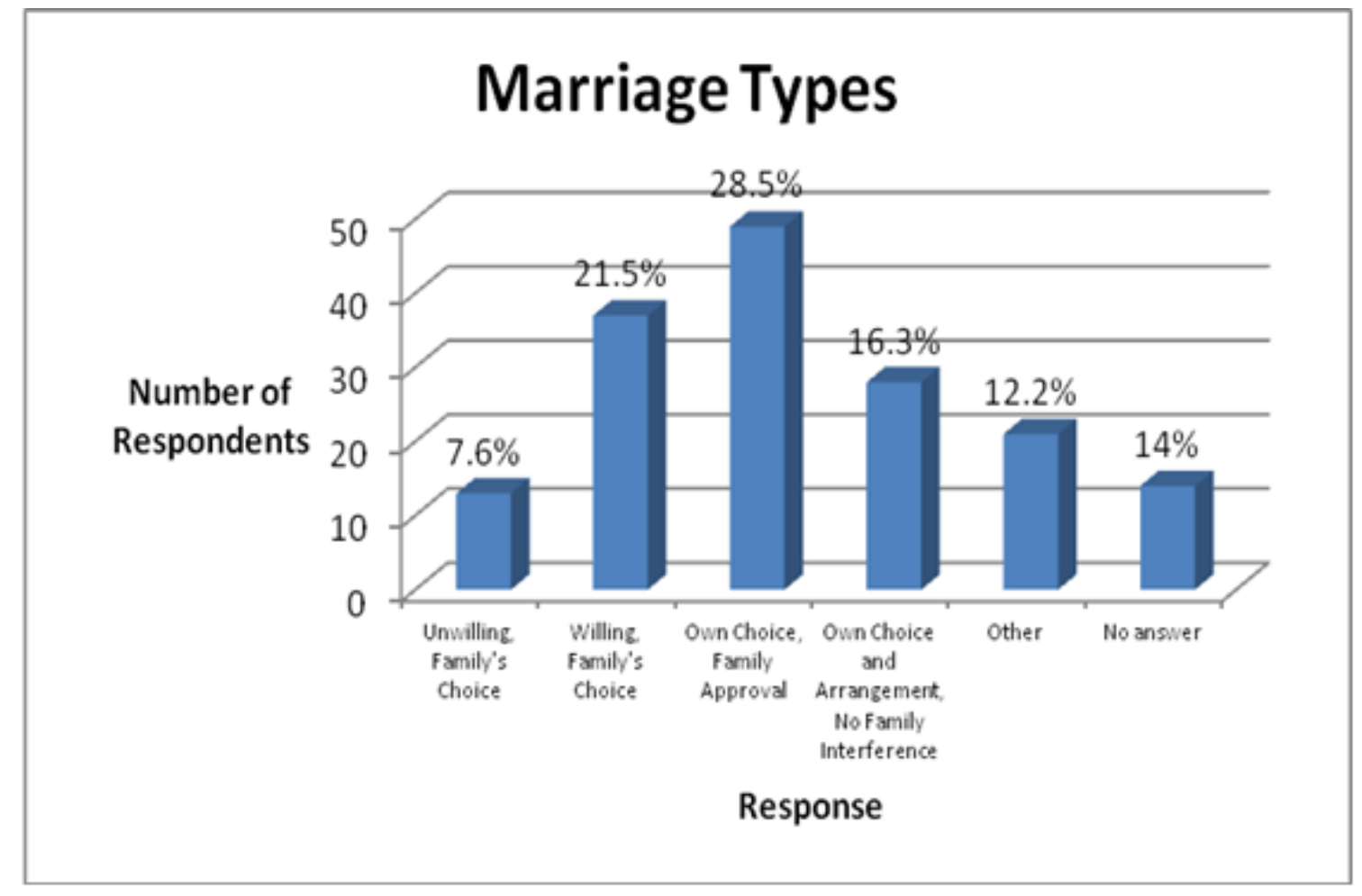

\section{Table 1: Marriage types}

Choice of marriage generally seems to be highly valued in the community. The significant portion of parents who accept their child's choice in marriage indicates a noteworthy level of trust in their children's decision making abilities and decisions themselves reflecting a higher quality of relationships in the community.

The amount of time community members spend with one another is indicative of the closeness of the community and proximity members live to one another. The table below indicates the frequency of visits members of the Kazak community pays to one another (Çiğgem, p. 70). 


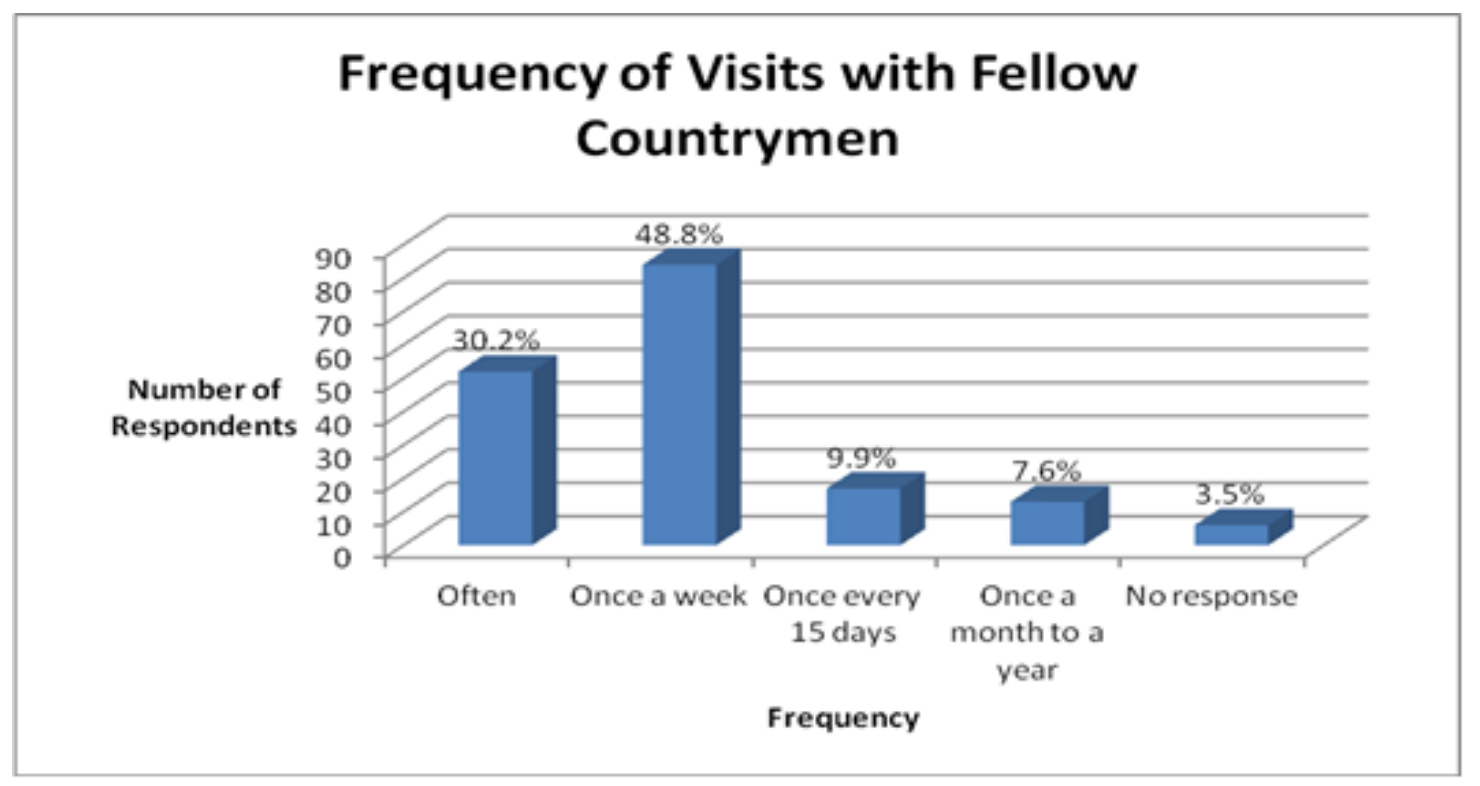

\section{Table 2: Frequency of visits with fellow countrymen}

This data infers that Kazak community members have close relationship with one another and that $79 \%$ visit one another once a week or more.

Strong relationships with kin are also important to Kazaks for living well in an urban environment. According to the Table below most members of the community felt that strong family ties were crucial to succeeding in an urban setting. Based on this data, family structures appear strong while links across families within the community are well maintained making for a tightly-knit social fabric at the time of Çiğdem's study. 


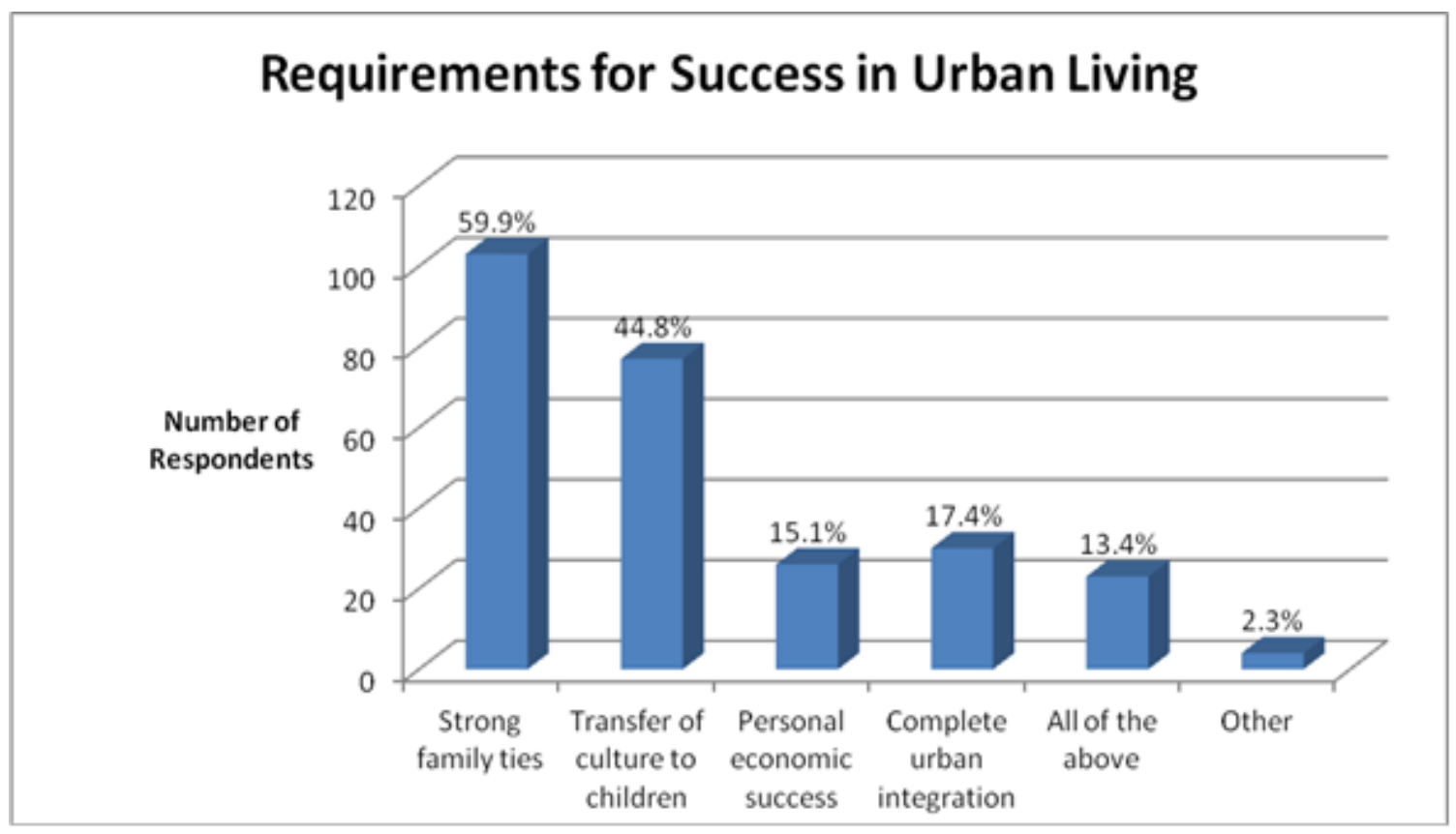

\section{Table 3: Requirements for success in urban living}

Education levels for the sample of community members who participated in

Çiğdem's study in 2002 show that very few continue on to higher education. Only $45.4 \%$ make it through high school and $54.1 \%$ attain middle school levels. 


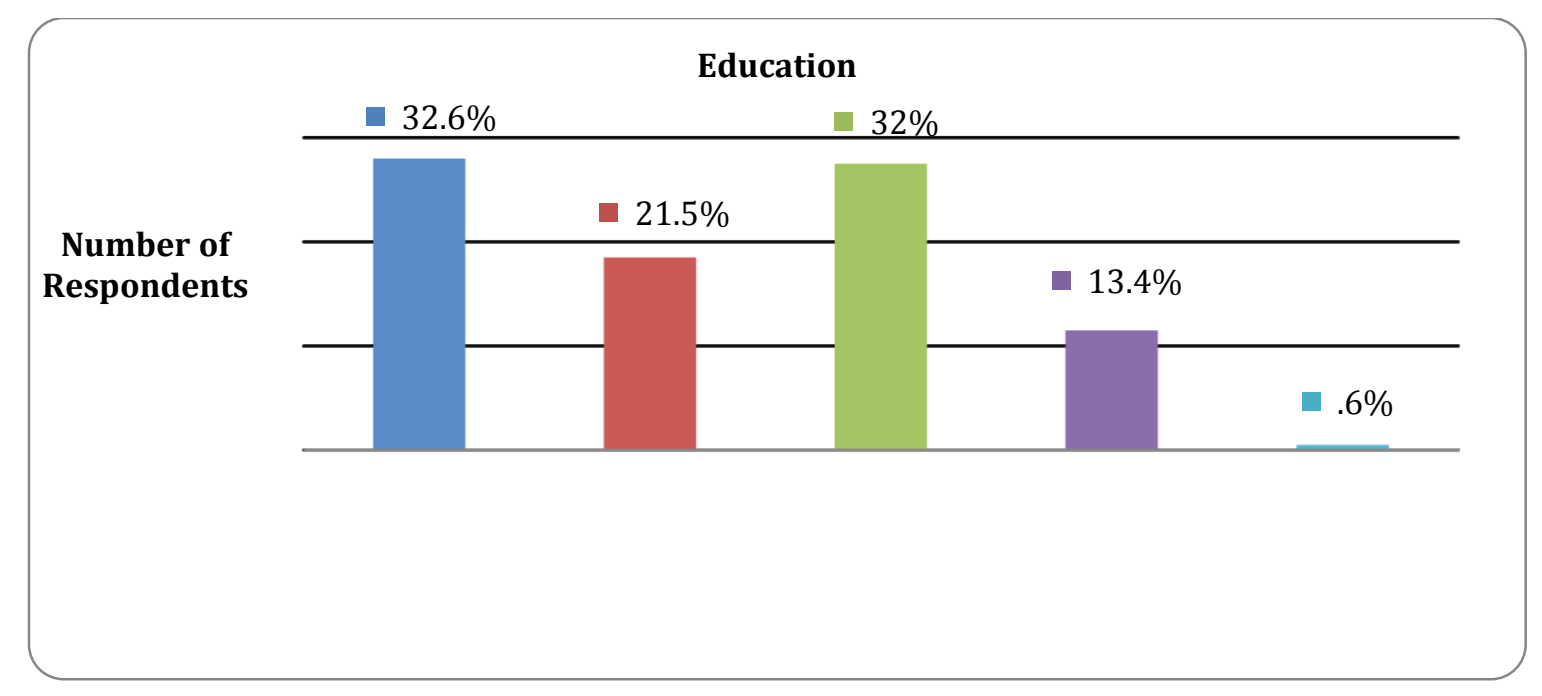

\section{Table 4: Education levels}

$$
\begin{aligned}
& =\text { Primary School } \\
& =\text { Middle School } \\
& =\text { High School } \\
& =\text { University Degree } \\
& =\text { No answer }
\end{aligned}
$$

The number of university graduates was relatively low in 2002 at $13.4 \%$ while the Turkish national average was $18 \%$ in 2008 (OECD, p. 26). The university system in Turkey is a reflection of a very competitive economy and a tight labor market where unemployment is high at $18.6 \%$ in the 15 to 24 age bracket (Vela). This creates a great deal of pressure on youth who spend long hours studying for university exams and are often burdened by a university entrance system that is arbitrary to their academic goals.

In the first decade of 2000 (2000-2010), earnings among the Kazaks averaged relatively low. Some $20.3 \%$ reported earning 100 - 249 YTL (New Turkish Lira), 37.2\% reported earning 250 - 499 YTL, 29.1\% earned 500 - 999 YTL, and 7.6\% reported earning 1,000 - 2,000 and above (sample size: 172 respondents, $65.2 \%$ male and $34.9 \%$ female) (Çiğdem, p. 86). The minimum wage for an individual in 2002 was 250.87 YTL (Özgün Ekonomi ve Makale Arşivi) with one fifth of the Kazak population earning less 
than or equal the amount needed for minimum sustenance, almost two-fifths earning up to double the minimum wage.

There is something of a sense of sadness among some early community members who remember or who vicariously identify through certain cultural activities closely linked to what it means to be Kazak. Many of these activities are spatially important and require open land or large space - the traditional Kazak horseback sport of kokbar - for example. The preparation of traditional foods which requires an open fire and cauldron is another such activity. The production of an array of non-pasteurized dairy products necessitates the possession of livestock. When the Kazaks first arrived to the neighborhood, there were more opportunities for some of these activities due to the nature of housing at that time which was typically one or two story detached homes with adjacent yards where animals could be kept. The dense spatial character of Istanbul in general and the Zeytinburnu neighborhood specifically makes these activities impossible. Changes in the neighborhood since the Kazaks originally settled in Zeytinburnu have been drastic with gecekondu, literally buildings built illegally by night, filling in empty lots between existing buildings and creating a tighter, more closed urban fabric. The inability to engage in certain culturally reproductive activities contributes to a feeling of loss of identity.

The Zeytinburnu neighborhood itself is a vibrant mix of many Central Asian groups and is called "China Town" by Turks because of the Asiatic features of many of the neighborhood's inhabitants. It is regarded as a migrant center for primarily Central Asian groups. The Kazaks were one of the first of these groups to establish themselves here. 


\section{Chapter II. The Literature and Methodological Approach}

This study draws from literature concerned with economies, urban communities and the mechanisms that link these two components together. The literature on refugees and innovation is particularly relevant to the Kazak as is the literature on ethnic enclaves, social cohesion and capital. The economic literature selected for this study is use for framing the greater economic context which the Kazak community is placed. The literature on ethnic enclaves, social cohesion, social capital, and moral economy is useful for analyzing the finer mechanisms by which the Kazak community functions socially as well as economically. Limitations arise from scholars such as Putnam who writes purely on the historic North American case of the loss of social capital and cohesion. Many of his examples are not applicable to the Zeytinburnu Kazak case such as the ways media entertainment are consumed in the U.S. versus in Turkey and more specifically in the Kazak community however, many of his general concepts are applicable and similar patterns can be discerned between the two cases with some interpretation such as the post-WWII patriotism in the U.S. and the post-exodus of the Kazaks in Turkey both as catalysts for higher levels of social cohesion. During the course of research, some theories were abandoned as no longer appropriate such as the literature on ethnic enclaves and others added such as theories on the moral economy which seemed to describe certain elements of Kazak pastoral society perfectly while finding new manifestations in the urban economic context. The key scholars that informed this study and provided its theoretical framework are Herman Daly and John Cobb with their analysis of the dominant growth-based capitalist economic system and a communitybased remedy, Robert Putnam who delves into social capital and cohesion as forces that 
prevent the atomization of individuals in society, Karl Polanyi with his economic and social theory of embeddedness which is a global phenomenon in pre-market and global capitalist structures, and James C. Scott who presents a depiction of the moral economy and its function for maintaining strong ties between the rich and the poor and the wealthy's obligations to sustaining the lives and livelihoods of the poor. These are the most critical theorists to this research. Many more were engaged to round out the discussion and provide complimentary or complicating viewpoints and theories.

\section{Refugees and Innovation}

Refugees are typically thought of as burdens to their host communities and dependent on humanitarian support. Many host populations and governments underestimate the economic power and skill base refugees bring to their new places of residence. In many cases refugees are significant economic actors. A study by The Humanitarian Innovation Project demonstrated that in Uganda 39\% of the over 200,000 refugee population were employed by others and an astonishing $60 \%$ were self-employed economic actors (Betts et al, 2014). Many of these self-employed refugees generated employment for local Ugandans. The study also found that refugees were part of international trade networks, connections that they brought with them to their host country. The perception that refugees are passive receivers of aid and lack skills to thrive in their host countries very rarely, if ever, holds true (Forced Migration Review, 2014). Often, they see learning the local language, gaining skills and entrepreneurial training as the most expedient path to self-sustainability. Many find ways to create businesses of their own using skills brought with them or acquiring new skills in combination with an analysis of previously unexplored business opportunities by the host community. Thus 
they are often able to exploit new markets and create niches for themselves offering goods and services that did not previously exist (Forced Migration Review, 2014).

\section{Economics for Community}

The notion of an economics for community as proposed by Daly and Cobb is central to this paper (Daly, Cobb, 1989). The current global capitalist economic system based on a model of increasing productivity for the aim of improved quality of life necessarily places growth as the number one priority. The growth of economies for the sake of growth is often criticized as a hollow undertaking, this particularly in light of its associated problems such as climate change that has global carbon emissions in 2010 increasing by $6 \%$ (The Guardian newspaper). Growth is often used as a primary indicator of national prosperity; however Gini coefficients often do not correlate happiness and well-being with high levels of growth. For example, in the need to show ever increasing GDPs, major dam projects may dislocate entire communities resulting in their destruction and disbursement to the nearest urban centers. Development in the name of growth is often carried out against the communities and citizens who are usually claimed to be its ultimate beneficiaries. As long as commodity exchange is based on the cost of labor, communities will always be vulnerable to the relocation of jobs or the invasion of cheaper goods that compete with the community's own production. The high mobility of capital sources in turn demands that workers simply move to where capital has established itself without calculating the loss of social relationships and other important social aspects of community. This can be immensely disruptive to communities and puts societies in a constant state of low intensity turmoil. It is highly 
disempowering to individuals and communities who require collective action to realize common goals and to resist disruptive pressures. To this effect, Daly and Cobb state that "The individualistic model of economic theory leads to advocating policies that weaken existing patterns of social relationships" (Daly, Cobb, p.163). But the authors also argue that unattractive alternative to communities with higher quality social relationship based around some kind of traditional organization is very low productivity (Daly, Cobb, p. 162). This may be the cost of relative stability and may signify a limited participation in the global economy. It, however, reflects a choice between slow, steady development through security on the one hand and a more thorough articulation to the economy for maximum productivity and profit on the other.

The definition of community itself is elusive but the term is clearly outlined by the authors. A society requires three elements in order for it to be called a community according to the authors. The first requirement is extensive participation by community members in the decisions by which life is governed. The second is the taking of responsibility for its members by the society. The last requirement is a respect for the diverse individuality of these members (Daly, Cobb, p. 172). Community is recognized as important "for the realization of common values in support of social goods, in allocating public safety, norms of civility and mutual trust, efficacious voluntary associations, and collective socialization of the young as well as for economic resources and social structure differentiation" (Sampson, p. 165). Sampson's theory of community social organization is defined as the "ability of a community structure to realize the common values of its residents and maintain effective social controls, the capacity of a social unit to regulate itself according to desired principles, to realize collective as 
opposed to forced goals" (p. 167). For these to exist, place is essential and the "community-liberated" notion of urban community where modern urbanites create social networks throughout the city while not necessarily knowing their neighbors is often not the community model that typically contains members of mixed class, race, income and interests. Wendell Berry's concept of community as "the locally understood interdependence of local people, local culture and local economy," however, is closer to the mark (Sampson, p. 182).

\section{Embeddedness and Moral Economy}

One general approach to understanding the modern economy can be summed up as follows: "social outcomes are analysed as resulting from the simple aggregation of actions taken by rational agents making decisions in isolation from other agents" (Krippner, p. 2). Neoclassical economics (as part of the utilitarian tradition) "assumes rational and self-interested behavior is affected minimally by social relations" (Granovetter, 1985, p. 481). This particular orientation towards economic satisfaction negates the responsibility of community members towards one another and also ignores motives that are beyond the explanatory means of rational actor theory. The process of modernization and its separation of social obligations from economic functions is central to the concept of embeddedness and how the economy is positioned in relation to a society's social relationships.

Karl Polanyi (2001) discusses the pre-free market arrangements of the economy as one embedded in the existing social relations. He is primarily concerned with the integration of the economy into a broader social system. After the development of the 
free market, the relationships between the social order and the existing economy were transformed and the situation became reversed. Social relations were, after this point, embedded in the economic functions meaning that economic activity took a primary position in the organization of society and social relations were in effect a by-product of those economic activities (Polanyi, 1944). The consequences for social organizing are much discussed by Granovetter, Krippner and others and one of the significant outcomes discussed by Polanyi is the complete autonomy of the economy itself described as almost lifted off of and hovering above the realm of modern society to operate of its own "free will.” Social Welfare Programs such as workers' compensation were institutionalized in Europe in the late $19^{\text {th }}$ century in varying nations and served to replace the social safety net that was lost in the separation of the economy from its social integration. A layer of social security and safeguards had to be reintroduced into the social organization of society to replace the loss of mutual aid for stability to be maintained. Without these, the mass of unemployed could create chaos and upset the workings of the free market, as the theory goes. It was essentially a system of social responsibility that insured the weakest against ruin as discussed by James C. Scott in his analysis of moral protection mechanisms through a social order (1976, p. 41). This new arrangement, however, had the social relationships "modernized" out of the economy. The result is the externalization of obligations that were once the function of social relationships and where there is excessive individualism in absence of civil society there is a large state that provides for all needs (Fukuyama, 2001, p. 11), a situation which emerged out of industrialization and massive urbanization as traditional rural social relations broke down. This notion has been much grappled with and challenged by Robert Putnam who 
claims that "social trust and group membership are positively correlated with bigger government," a phenomenon he cites as highest in places like Scandinavia, places which also have very comprehensive social welfare programs (Putnam, p. 281).

The detachment of social responsibility from the operations of the economy is something that the welfare state in the advanced stages of capitalism attempts to right and replace by creating social safety nets such as unemployment, public health insurance, and social security. It is an attempt to superimpose a layer of socially responsible and moral relations back onto a society oriented on a singularly extracted market orientation. If the functions of the modern economy have not led us to act immorally, as the argument goes, then they have at least led us to act amorally (Sayer). In addition, some argue "that in removing responsibilities from individuals and socializing their fulfillment, the welfare state's effect was to increase the individualizing effect of modern society, enhancing individuals' rights while reducing responsibilities" (2000, p. 13-14). The question lingers of whether or not people of differing social strata really did behave with greater moral tendencies towards those in lower strata as dictated by more socially oriented socioeconomic norms before the emergence of a market economy. Networks, for example, have been seen as a kind of contemporary moralizing phenomenon that link individuals to greater opportunities. Sayer, however, argues that networks operate on the basis of personal self-interest as corresponds to the self-interest of other members of the network and that the benefit to others or society is of negligible concern.

In pre-market feudalistic as well as in post-market peasant economies, there existed a minimum moral requirement for wealthier members of society (land owners in particular) to ensure the subsistence of those less wealthy (peasant tenant farmers) (Scott, 
1976). This social contract existed, among other places, in the villages of South East Asia where "informal social controls ... act[ed] to provide for minimal needs of the village poor" (Scott, 1976, p. 41). The wealthy thus were bound by social requirements to provide for poor community members. This was an insurance against instability and Scott acknowledges that in no way were poor villages granted equal income or equality but rather they were granted "a place" (1976, p. 43). The right to subsistence governed the lives of the poor and while they perhaps could not do much to improve their lot they were assured against starvation. Implications for not respecting this right by landowners and other capital holders could be and often resulted in the form of political opposition, rebellion, violence, and instability. The costs of allowing the poorest of the poor to become too impoverished were much greater than the costs of maintaining their basic level of subsistence and the wealthy classes saw their stake in ensuring that this was so.

The increasing disappearance of this type of socio-economic organization may come at a great cost to governments who are now bound to provide for the needs of many citizens who may otherwise have been able to provide for themselves in other ways. Scott sites various sub-regions in agrarian South East Asia as his case studies. Prior to government annexation and the privatization of public lands, subsistence farmers were able to use the free public good of the forest and natural fisheries to supplement their subsistence needs. Once these lands were annexed and sold or rented to the highest bidder for needed revenue, many subsistence farmers now had to pay for the services these marginal lands provided. If unable to pay, peasants necessarily resorted to assistance from the state, emigration, or rebellion. The state may be petitioned for help but it may lack the resources to provide any and the share of resources allocated to 
peasant farmers to subsist free of monetary cost is now in the hands of an entrepreneur who uses it to create surplus for himself. In such cases, the state may be unable to extract that surplus to reallocate it to the peasant farmers who need it to survive and originally used it in the first place.

As these previously accepted moral rights have become increasingly monetized and removed to the handling of third parties the risk is that the ability for self-advocacy becomes diminished. If democratic processes are not advocates of the poorest members of society these poorest members will inevitably be excluded from its benefits. Whereas they were previously able to provide for themselves by evoking their moral rights, in an amoral economy they may have no real claim to a place in the functions of the economy. This is significant for the Kazaks who maintained a form of this social welfare as a function of a social economy in western China and continue to provide such temporary support to persons in need from the community.

\section{Ethnic Enclaves}

The literature on ethnic enclaves, defined as a physical neighborhood or otherwise spatially defined where its residents reside and agglomerate based on choice that may be linguistic, ethnic or nationally determined, offers an economic approach to understanding the benefits that ethnic migrants gain through participation in the enclave economy. It is also useful for defining the parameters of the community's activities and for defining the type of community we are looking at. A common language is certainly a factor that facilitates spatial and firm concentration and creates a unity through which members can benefit economically. First choice for co-ethnics in the labor market will likely be 
through linguistic ties as their economic opportunities will be better than in markets that operate in a language in which they have less proficiency (Bauer, 2005). In the Kazak case, Kazak is closely related to Turkish and prior to relocation to Istanbul from their first settlement sites in Central and Western Anatolia, they received Turkish language instruction to assist their assimilation. Language was less of a factor for their spatial concentration than a common culture and a shared sense of community through clan affiliation and hardships experienced in the migration process from Xinjiang, China to Kashmir, India, Pakistan and finally to Turkey.

Some myth may surround the nature of the ethnic enclave. Some of the negative effects of spatial concentration in an ethnic enclave which have been widely discussed in some of the literature are presented as resembling concentrated poverty. In England and Wales, minorities experienced little benefit from concentration. There the average deprivation increased as ethnic minority concentration increased (Clark, 2002); however as the quality of the enclave increased so did the positive effects of enclave concentration and the lower stratum experienced increased benefits (Edin, Fredriksson, Alsund, 2003). These findings correspond with income and spatial segregation data. The neighborhoods that least resembled enclaves were more likely to have a higher incidence of minority entrepreneurship. This is contrary to the pattern of protected markets often seen in ethnic enclaves and in the Kazak case entrepreneurship makes up the majority occupations. An alternative model for the ethnic enclave organization may resemble a cooperative-style arrangement where the benefits of the enterprise are partitioned among its members in which community and economy are intimately bound. This model is a closer fit to the one initially formed by the Kazaks in their initial years in Turkey. 
While finding a niche in the local culture and economy, globalizing trends have had an effect on expressions of local identity. The rural to urban migration context in Istanbul is framed along integration lines and a migrant group's ability to integrate is directly related to its contact with the city. Participation in the city is dependent on access which may be limited by a migrant's accent, making him or her feel as a nonurbanite and there may be pressure from other migrants against urbanization which may be viewed as selling out. This pressure may serve to increase social cohesion at the neighborhood level. Many second generation migrants in Istanbul feel unqualified, that is do not identify, as urbanites or villagers. Since the 1990s, these ethnic identities have been increasingly recognized and encouraged more than in the past (Erman, 1998). The Kazaks, moving from a nomadic way of life to a rural then an urban one may feel the compound effects of being rural as well as being foreign but the greater factor is their actual emigration from abroad. Discrimination from locals might have been an issue had labor competition been a factor of their settlement in Istanbul, as has been the case among migrants to American cities (Dustmann, 2001). However, as they have primarily moved in to fill an abandoned sector left vacant by migrating Jewish and Armenian populations, they were likely to have been viewed as reinvigorating a much needed sector and thus moved into relatively conflict-free relations while maximizing their opportunity. Later, during the political strife of the 1970s and the 1980 coup, the community's access to the city was restricted as it became unsafe to go to school, work and for women to be out because as Central Asians, they were perceived to be communist supporters and thus leftists in danger from the active rightist groups in Istanbul. There is evidence that this 
created a retractive response from the community and measures were taken to limit the interaction of Kazak girls with non-Kazak boys under the guise of protection.

Employment opportunities for ethnic migrants are often dependent on possibilities of economic protection from within the enclave. The segmentation of labor markets can exclude or include immigrants but where an enclave option is lacking immigrant groups may cluster into secondary and informal forms of employment as in the case of Cuban and Haitian immigrants in southern Florida in the 1980s (Portes, 1985). The historical form of immigrant adaptation when faced with low-paid jobs and precarious labor markets was to form tight-knit communities for support and protection. Participation in the enclave economy was dependent on being of the same ethnicity as the firm owners which meant exclusion for Haitians. In his scenario, we witness little benefit extending out from the enclave community to the larger population. The economic development created by the Kazaks, however, extended first to the villages of their early settlements which lacked significant economic activity, and then, to a lesser degree, to other Central Asian migrants in Istanbul.

\section{Social Capital and Cohesion}

Ingvar Svanberg (1998) in his study has described a strong Kazak community in Istanbul based on cohesiveness and the importance of cultural activities. His fear was that the community would in the near future begin to lose its cultural identity with the young generation, as is to be expected, but that at the time of writing there was much participation from various parts of the community. Svanberg, a cultural anthropologist, 
looked at the movement of this group of Kazaks from western China upon fleeing a communist regime they opposed and rebelled against through their movement to Srinagar in India and then Pakistan where they first began sewing leather garments to supplement their incomes. He spent time with the Kazak community in Istanbul and found that there was a resurgent youth interest in Kazak culture that started in the 1970s based along panTurkist ideas and related to pan-Turkist conservative organizations (Svanberg, p. 167). Kazaks he spoke to conveyed a sense of superiority and positive self-identification in relation to Turks due to the hardships they underwent on the journey to Turkey and a notion of their heroic past (p. 183) contributing to a cohesive society. He states that the economic success of the community fed into this positive self-identification.

Understanding how ethnic enclaves operate to create their own thriving economies provides a scenario based on social cohesion and traditional value systems for a study of community economic success based on strong ties. Putman argues his case for the positive aspects of and need for social capital pointing out that social capital "helps us to more easily resolve collective social problems" and thus is important for community mobilization (Putnam, p. 299). This is a key principle in community development activities.

The definition of social capital put forward by Janjuha-Jivraj is based on a web of cooperative relationships between citizens that facilitates resolution of collective action problems (Janjuha-Jivraj, 2003). The embedded networks essential to ethnic networks rely on the unquantifiable qualities of trust, personal relationships, dyadic interaction, what essentially all amount to social capital. The maintenance of kinship networks, important to social capital, will last as long as ethnic groups are not able to prosper 
without them, indicating the need-based nature of ethnically cohesive forces.

Fragmentation is not a stranger to the Kazak community in recent times as many young community members orient themselves towards the greater urban and national communities setting the clock ticking on the continued usefulness of kinship ties.

Chan, To and Chan (2006) define social cohesion as "a state of affairs concerning both the vertical and the horizontal interactions among members of society as characterized by a set of attitudes and norms that includes trust, a sense of belonging and the willingness to participate and help, as well as their behavioural manifestations" (p. 290). They use Putnam's definition of social capital to demonstrate how it differs from social cohesion and write, "Putnam, who defines social capital as "features of social organization, such as networks, norms and trust that facilitate coordination and cooperation for mutual benefits" (Putnam, 1993, p. 36). The distinction they offer is between the mutual benefits-based relationship of social capital and the feelings-oriented one of social cohesion. The second, they claim, is more holistic and is concerned with the affairs of society as a whole and the primacy of the collective over individual is important to social cohesion but not social capital (Chan, 2006). The authors also offer useful measures for social cohesion based on trust, identity, and social participation:

1) they can trust, help and cooperate with their fellow members of society; 2) they share a common identity or a sense of belonging to their society; 3 ) the subjective feelings in (1) and (2) are manifested in objective behaviour. (p. 289)

These guidelines provide us with a means to understand the degree of social cohesion present in the Kazak community. This indicator holds true in many ways for the older generations who either experienced the difficult migration themselves or who are closer 
in generation to those who did. The binding together of individuals in times of hardship is common and is much discussed by Putnam for the U.S. 1940s generation who experienced the solidarity of the war. For the younger generations of the Kazak community this measure seems to indicate that a loss of cohesion is occurring while the older generations possess stronger personal motivations based in lived experience or the second-hand lived experience passed on from their parents.

The durability of the Kazak's social network is a key issue in the discussion of social capital in communities. Their durability is based in kinship ties which include spouse selection practices that even span international boundaries. Bourdieu's addition to the definition of social capital (Portes, 1998, p. 3) involves the aggregation of resources linked to a durable network thus making the link between cohesive community and the mobilization of resources. Portes argues for a precondition for social capital. The investment of both economic and cultural resources is necessary for the acquisition of social capital in his analysis (1998, p. 4). He uses Bourdieu's claim which "makes clear that social capital is decomposable into two elements: first, the social relationship itself that allows individuals to claim access to resources possessed by their associates, and second, the amount and quality of those resources" (Portes, 1998, p. 3-4).

The functions of social capital have also been illustrated to be a source of social control, a source of family support, and a source of benefits through extra-familial networks. When community social controls are replaced by those of an institution the implication is that social capital shifts to that institution. The use of social capital by ethnic enclaves is not always positive. It may be an excluding force restricting the entry 
of outsiders, imposing excessive claims on group members, imposing restrictions on individual freedom and downward leveling norms as opposed to upward leveling ones.

Higher levels of mutual aid and stronger family ties associated with the poor assists them in coping with the hardships of poverty. Social cohesion is important for the operation of such mutual assistance and where it is lacking, social disorder, conflict, disparate moral values, extreme social inequality, low interaction levels and low place attachment levels exist (Forrest and Kearns, 2001). The reaction of the Kazaks to create a distinct neighborhood of their own called Kazak Kent reflects what the authors call the 'neighborhood as commodity' and represents internal cohesion at the expense of external relations and appears to be a strategy to stave off social fragmentation.

\section{Methodological Approach and Research Design}

\section{Research Methods}

To reiterate, this research operates under the assumption that community is important for the realization of common goals and mutual benefit and that there are powerful reasons for maintaining strong communities as has been demonstrated by Robert Putnam. ${ }^{1}$ The need for social capital in order to achieve political goals is the key interest of Putnam's work and is relevant to the Kazak and other communities for potentially achieving their economic goals. The further purpose of this research is to examine the nature of the social capital and cohesion that exist in the community and to find out if this has a positive effect on the community's economic activities. The moral economy question is one that is closely connected to the social relationships within the

\footnotetext{
${ }^{1}$ Putman has claimed that the benefit of social capital is its role in assisting communities to more easily resolve collective social problems and has demonstrated its benefits to communities ( $\mathrm{p} 312$ and 317).
} 
community and is a function of the embeddedness of these economic activities in social relationships. Social capital as a channel for the distribution of moral economy activities is important to this research. I intend to answer this question as a case of communitybased economic organization as a viable means of economic positioning. The approach I use draws from Robert K. Yin's case study methodology (Yin, 2003). This case study is a single case embedded design that is both descriptive and explanatory in character and seeks to determine the nature of the Kazak economy and the relationships that are involved in its operations whether they be positive or negative. I will also explain why the Kazak economy has arrived at a weakened economic state and its relation to the key theories of interest to this research such as social capital and cohesion, economic embeddedness in social relations and the functioning aspects of a moral economy.

This research depends on several literature areas. These include literature on social capital and cohesion, literature on ethnic enclaves and the literature on the moral economy and embeddedness as discussed above. Organization websites, newspaper articles, and interviews with key informants are the primary sources for this research. Data collection involved the use of in-depth semi-structured interviews with open-ended questions and unstandardized interviews as well as participant observation as the main modes of data collection. Oral history as well as narrative interviews were also used in this research when they became pertinent to the research question. In-depth interviews were used to follow up with key informants to delve deeper into particular issues brought up by those or other informants about the community. Through participant observation, I observed the cultural foundation that serves as an important social cohesion and capital focal point in the community, the ways in which the greater community is involved in 
this institution, the modes of social and cultural reproduction such as marriage expectation and desires, linguistic practices, and cultural promotion and how these act to tie together members of the community, the points of contact between the political and economic interactions of the community, and the level to which younger generations reproduce community and cultural values.

The unit of analysis for this research is the Kazak community in the Zeytinburnu neighborhood in Istanbul with the embedded units being the community's main cultural organization and key individual informants which were used to gain a concept of the state of the greater community including political figures and business owners. While initially intending to examine multiple social classes within the community access proved to be somewhat challenging due to issues of trust. Here I should clarify that this study is mostly limited to community elites and Kazak cultural advocates. My first point of contact to the community was through the Kazak Türkleri Vakfı (the Kazak Turk Foundation) in the Zeytinburnu neighborhood of Istanbul. The Foundation is primarily a center for the promotion and continuation of the culture and beliefs of the Kazak community and was founded in 1986. It acts as a focal point for community and cultural events, traditional weddings, Koranic classes for girls and boys, some degree of religious messaging related to a Kazak cultural identity, communication with representatives of the government of Kazakistan, and for material assistance to the poorest members of the community. It represents an older segment of the community who primarily want to ensure a continuation of the "original culture" of the community before they arrived to Turkey and less represents the majority of youth and young adults who were born in 
Turkey - primarily the third generation. Some of its functions as listed on its website include:

a) To educate and build the capacity of youth within the framework of Turkish and Islamic culture and national and spiritual aims. This includes providing assistance such as scholarships, financial support.

b) To provide for the poor and needy who lack other means of support and to house the elderly.

c) To assist the poor and needy in examinations and treatment of health problems.

d) To provide a space appropriate for weddings in the Turkish-Islamic traditions and to organize the appropriate activities.

e) To sponsor conferences, seminars, and courses in accordance with the law and in the capacity to teach community and Islamic traditions to the youth.

f) To publish materials on our cultural heritage from academic conferences, seminars and scholarly research.

g) To produce and publish work on the major figures of research of Islam, nationalism, religion and science.

h) Publish a magazine on the topics of Islam and nation when possible.

i) To assist families in need with weddings, funerals and burials and births.

Some of these will be discussed more later.

The manager of the Foundation, Abdülselam Malkoç, was a key informant for this research and facilitated introductions to other key community members. Interviews were held in cafes in the neighborhood and in the Foundation itself and were mostly arranged in advance. Random interviews were also conducted when appropriate and when unscheduled visits were made to the Foundation. The aim of unscheduled visits was to access informants that may otherwise not be available from scheduled interviews and to add a random selection process to the research design and interview schedule. A conversational interviewing approach was used for these interviews due to the casual nature of the encounters while semi-structured interviews were conducted with scheduled respondents. 
Kazak informants from outside the community were also interviewed to attempt to triangulate the position of the Kazak community in terms of culture and cohesion. These informants were university students from the same area of Xinjiang who came to Istanbul to study and who have relatives within the Kazak community or who have contact with the community in other ways. Their views were important for their perspectives as insiders but non-participants in the Kazak community. The use of multiple sources of data through interviews with multiple respondents and interviews methods of differing types, past research on the community and existing data coupled with attempts to triangulate information as much as possible were used to address the issue of construct validity.

External validity has been verified by the theories this research is based on such as social capital and cohesion theories and the theory of the moral economy. The findings bear evidence of these theories and their operation in the community. The generality of the theories is found to be true in varying degrees in the particular case of the Kazaks of Istanbul.

In approaching this community and analyzing the data, it was necessary to be aware of the constraints of the informant's own filter which he uses to select and present the information he wants presented to his readers. As researcher, it was important to keep in mind that information I was dealing with, while meaning very little to myself on a very personal level, meant significantly more to the identities and self-image of my informants. For the informants, there was a very personal stake involved in the information they were sharing with me as it reflected on their community and identities within that community and for this reason there is likely a guarded and filtered quality to 
some of the information I was able to obtain such as the repetition of the community's migration narrative by many informants as a potential way of indoctrinating the researcher. When interviews were recorded, respondents often assumed an orator's demeanor and information took on a more dogmatic and purposed quality. It was sometimes useful to allow the course of this demeanor to run itself out and it was sometimes better to switch to note taking.

\section{Interviewee Selection and Nature of the Questions}

The selection of interviewees involved snowballing techniques deemed most effective in find specific key informants beginning with the Kazak Turk Foundation in Istanbul as the first point of contact. These informants comprise community leaders and second generation business owners as well as other members of the community including those in the municipal government. The focus of these interviews were aimed at understanding the process by which they came to enter positions of power and inquire into the social relations developed through the phases of the community's economic progression that made it possible. The interviews also make an inquiry into the incentives of third generation business owners to maintain their ties to the community. They will also determine what is the nature and strength of those ties and the relevance of political involvement in maintaining a close-knit community. If these members of the community see themselves as moving beyond the community, inquiry will follow to assess how and why. 


\section{Challenges}

In the later stages of my contact with the community, it was revealed to me that some community members suspected me of being a spy. The confession came as little surprise because of the guarded nature of some of the responses I had received earlier on. Because of the socio-economic interest of the research I could not really understand how the community perceived that I could cause them harm. The likely candidates for whom I could be spying for were the Turkish government as the Turkish government may be skittish about any community migrating from a communist country despite the fact that the community might have fled communism in the first place and the Chinese government for the political sensitivity over their Turkic populations in Xinjiang. The Kazaks reported such accusations from Turks especially in the 70s and 80s during the political instability and subsequent clamp down of the era. Despite being "original Turks" coming from the historical homeland of Turkic peoples, a notion so often celebrated by Turkish nationalism and Pan-Turkist thought, on a kind of practical level they were also perceived as different and foreign and viewed with suspicion. Under these conditions, the community faced attacks of character and accusations of treason and so maintained a conservative political position for self-protection. They maintain this position today, a position which likely contributes to a guardedness on certain subjects. Information that may prove damaging or invite threats to the community is likely to be highly guarded. In a society such as Turkey's where statements criticizing the founder of the republic, Atatürk, or statements that are perceived to be against "Turkishness" are illegal and land individuals in serious trouble which can even go as far as torture, it is understandable that the Kazak community would be protective about certain kinds of 
information. The potential for information to bring serious harm to the community is a possibility where freedom of speech and expression are curtailed. The community may be uncertain as to what kind of information about themselves may be damaging and so may take extra care to protect such information.

Their hospitality and openness, however, was striking to me as a researcher and I was able to spend hours at a time with some informants. That said there were times when I felt that information I was receiving was oft repeated and ready information concerning topics relating to a historical narrative of their communal history. Since I was not carrying out a discourse analysis, this was not the topic I was interested in and it was often necessary to wade through the thick of this unneeded information and steer us back onto the course I had plotted out for my objectives. Divergences were welcomed when it led informers to share unexpected information of interest to the research question. Longer lengths of time spent with some participants led to unexpected insights through information that was revealed in the form of a kind of confession. The long time spent together with one participant may have induced a feeling that I was waiting for a particular piece of information which was at long last revealed. There was no such goal and the information was revealed after it was confessed to me that some considered me a spy.

Given all this, there were limitations to whom I could get access to. Some contacts that had been mentioned during the course of interviews did not materialize. The repetition of certain completely unrelated pieces of information pulled from the community narrative in response to some of my questions acted as walls behind which potentially rich information was kept sequestered. A step further or rather deeper into the 
community may be required to eventually get access to informants and narratives that shed more light on different angles of the Kazak story. This may take the form of staying with the community or taking a more participatory role in some of its cultural and social activities. Much thinking needed to be done about the data gathered. Although a strong identity narrative was oft repeated during interviews, respondents offered much candidness about their own roles and failures as well as the shortcomings and missteps of the community to maintain their economy. These gems needed to be sifted out of the community narrative and provide glimpses of honest self-criticism giving confidence to the reliability of much of the data as to the views of this particular layer of the Kazak community.

\section{Interview Questions}

Below is a framework of the basic interview questions designed to focus on the issues pertinent to the research. Interviews were structured to allow for revising the questions and asking additional questions to get at information or ways of getting information overlooked in the original design. These questions are designed to be openended to allow respondents to relay what information is important to them rather than conducting a researcher/interviewer oriented agenda. The interview process was allowed to evolve as new information was gathered and as new information became relevant to the findings. Political officials were interviewed last in order to develop as informed a platform as possible before approaching them and the interview schedule followed a method of intensification as described by Sayer for the accessing of more precise data as information became relevant (p. 244). 


\section{For Business Owners:}

1) Who do you typically tend to hire? Kazak, Turks or does it matter?

2) How many Kazaks do you have working for you and in what positions?

3) How many Turks do you have working for you and in what positions?

4) How many foreigners do you have working for you and in what positions?

5) Where are most of your sales oriented? Who are your targeted customers?

6) What forms of community activities is the company involved in?

7) Do you donate money to community projects, schools, support funds, etc.? What kind exactly?

\section{For Political Leaders:}

1) How would you describe your official duties?

2) How would you describe your involvement with the Kazak community?

3) Who do you have the most contact with in the community?

4) Who would you go to in the community to discuss a major issue that would affect the community?

5) How does the community assist you in performing your duties?

6) In what ways do you perform political functions that are specifically aimed at improving or maintaining community ties/involvement?

7) Do you feel that the community holds you accountable for improving its situation?

\section{For Foundation Officials}

1) What is the percent of relatively well off members of the community?

2) What is the employment rate within the community?

3) What is the dispersion of employment in terms of types of jobs?

4) Are there many job providers within the community and how much do those that exist hire within the community?

5) In your opinion, is the community's well-being being fulfilled?

6) How has education played a role in the community's success?

\section{Framework for Data Collection Approach}

Below is the approach used to guide the collection of data during the course of the research. It is the general guide used to structure the important components of the community. Some of the components were abandoned along the way as it became 
apparent that data was difficult to gather or that the component was not an issue relevant to the community.

1) How cohesive is the $21^{\text {st }}$ century Kazak community in Istanbul? Measure:

- Marriage, dating, etc. traditions/intermarriage with other groups?

- Employment practices - Hiring from mostly in-group? Is there much hiring from outgroups?

- Religious practices?

- Lending relationships

- Trust/social capital

2) What factors have contributed to Kazak cohesion?

Positive Factors

- Shared need - interdependence for economic success?

- Pride, cultural promotion?

- Linguistic

- Political leadership

Negative Factors

- Political leadership

- Wealth

- Education (undermines traditional values)

- Urbanizing

3) What is the role/impact of political leadership or political involvement on community cohesion?

- Do businesses seek local leadership or community advice or approval for major business decisions? What is the role of the community when it comes to Kazak businesses?

\section{Data Analysis}

Analysis of the data was conducted by sorting according to key themes that were important to the research question. These categories included benefits to the community of political involvement of members, incentives for business owners to stay tied to the community, incentives for youth to stay tied to the community, reproduction of culture, and benefits of Kazak community success to non-community members, the moral responsibility of the Kazak Foundation, space and continuation of culture, space and 
protection, education and its relation to cultural tradition, and the missed opportunity for political involvement. The individual cases were examined to determine the strength of the community in terms of the continued involvement of community members. Some measure of quantity was used in order to discuss the frequency and number of community members interviewed who exhibit close connections to the community.

Data was analyzed for evidence of social capital and cohesion and an analysis was made of the nature and quality of these. An interpretation of the remnants of the community's moral economy was made from the existing community foundation and its functions and activities and also using a historical approach with evidence from their pastoral nomadic past. The overall landscape of the community was analyzed through these components to attempt to get at a better understanding of where the community stands today and what forces led to this state.

\section{Organization of the Paper}

The rest of the paper will continue with a section on the background of the Kazaks before their arrival to Turkey, their time in the villages in the Turkish countryside and their subsequent move to Istanbul. The paper will then move into a discussion of refugees and innovation. This chapter will also involve a discussion of the meaning of the idea of an economy for community. It will offer the reader an overview of the discussion of embededdness of the economy in social relations and the nature of a moral economy in order to provide existing theory of the nature of a type of pre-modern economy and one that fits the case of the Kazaks prior to their migration from the Altai Mountains of Western China. In the following chapter, the ethnic enclave phenomenon will be discussed in order to understand the phenomenon that many ethnic migrants 
experience upon migrating to an urban area and to explain the urban and community context they created. Some background on ethnic entrepreneurs is necessary for this discussion and is included in this chapter. Chapter six delves into the subject of social capital and cohesion and examines the discussion in terms of the community's main cultural institution, failed opportunities for enhancing its social capital and the younger generation and its position in terms of continuing the propagation of community oriented social capital for future generations. Finally, the last chapter will discuss conclusions from the findings and their implications for the Kazak community from the perspective of the research question. 


\section{Chapter III. Background: The History of the Kazaks of Istanbul}

The Kazak community of Istanbul established itself in the 1970s during a challenging political period in Turkey's recent history. At the time, there were major political upheavals which pitted right wing factions against those on the left. The police had many right wing elements which tipped the balance towards the right. Violence spilled into the streets with right with and leftist enclaves designated at the neighborhood level. Streets were barricaded and any leftist venturing into a right wing neighborhood would be beaten or worse and vice versa. Political affiliation was highly polarized.

Prior to their settlement in Istanbul, the group was settled in several rural areas of Turkey's central provinces in specially built villages in the 1950s during a period of immigration of Bulgarian Turks who were forced to leave their homes in Bulgaria. It was within this context of refugee immigration of Turkish and Turkic peoples to Turkey that this group of Kazaks from Xinjiang province of western China was allowed to enter Turkey and settle. In Xinjiang, the Kazaks lived a nomadic way of life and were involved in horse breeding among other animal husbandry activities. They numbered around 440,000 in 1946 and the nomad economy comprised a significant part of the Xinjiang economy from 1911 to 1949 to which the Kazaks were important contributors. A portion of their economy was also based on trade with Russia as well as supplying horses to Chinese buyers (Svanberg, 1989, p 49). During the Republican era, the region experienced a shift from diversified to specialized farming and the ensuing industrialization in the cotton growing areas of Soviet Central Asia created a greater need for livestock which the Kazaks could provide. 
The politics of the region began to change around 1911 with the declaration of independence of Outer Mongolia. In response, the Guomindang government armed the semi-nomadic Kazaks, the community in favor at the time (Svanberg, 1989, p 49). Rebellion spread in 1931 when the regional Chinese governor abolished the Hami Khanate (the tribal leadership in the area) and attempted to force out local Turkic Uyghur farmers in the Hami oasis in favor of Han refugees fleeing starving conditions in the Gansu province. The situation was exacerbated when a local tax collector attempted to marry an Uyghur woman by force and rebellion spread with the Kazaks eventually joining on the side of the rebels. The rebellion came to rest but was reignited in 1943 by the Altai Kazaks in the wake of Han immigration and the takeover of Kazak pasturelands facilitated by the authorities (Svanberg, p 49). The local authorities conceded to the rebels in 1946 and agreed on taxation based on real productive capability, ability to pay and free internal and foreign trade. The third rebellion ensued after the arrival of the Chinese communists in 1949 and was abandoned the following year in futility. Under difficult conditions a group of 15,000 Kazaks fled to Srinagar, India then to Pakistan their numbers decreasing to 1,200 through loss during the difficult journey. They moved again to India and back to Pakistan after independence. There, their livelihood consisted of sewing skin caps, clothing and handicraft production.

Under Turkey's basic settlement law of June 13, 1934, migrants of Turkic origin who spoke "Turkish" received preferential status. In the wake of the 1950 expulsion of some 250,000 Bulgarian Turks from Bulgaria (ethnic Turks who spoke Turkish), the Kazaks were admitted to Turkey in key sites deemed strategically important in terms of either further Turkifying immigrants or Turkifying the local population depending on 
who was being settled. Their route from India took them from Mumbai to Basra by boat and then Turkey via Baghdad by train. The 1,892 individuals/564 families were settled in four key sites in central Anatolia after temporary settlement in refugee camps near Istanbul: Altayköy and Sultanhanı both in Niğde province, Kayseri in central Anatolia, and Salihli near Izmir. Under the classification iskan göçmen ${ }^{2}$ (settled immigrants) they received land, agricultural tools, housing, tax exemption for five years and from military service for two years. Housing was built by the Turkish government to quickly settle the new immigrants and also to strategically locate these groups in locales deemed in need of a Turkifying influence from a Turkic population, in accordance with nationalist immigrant settlement policy at the time. Citizenship was also immediately granted upon entering the country and vocational training in handicrafts such as carpet weaving and language instruction was provided, even though Kazak is closely related to Turkish.

Agriculture and cattle breeding were the Kazaks' main economic pursuits but their limited economic success in these endeavors lead to other activities that yielded greater potential. In each of the four primary settlements, leather workshops were founded by the Kazaks which made use of leather scrap from primary manufacturing centers such as Istanbul. The Kazaks began to manufacture leather clothing in a cottage industry based on cultural skills they had brought with them from their semi-nomadic lives in Xinjiang. They had with them certain material capital such as sewing machines which had been brought from Pakistan.

$2 \dot{I}$ skan göçmen was a classification of immigrant to distinguish from serbest göçmen (independent immigrant). An iskan göçmen had a right to tax exemption for five years and could delay mandatory military service for two years and often received other direct state benefits such as language instruction and other forms of training. In contrast, a serbest göçmen received no direct help but had a right to state loans for homes, land and businesses. 
The origins of this leather industry began in Istanbul when some Kazaks procured leather and hides to make caps and clothing. These were brought to the primary settlement of Salihli. Merchants in Izmir began to supply Kazaks with leather in exchange for sewing jackets out of scraps. These scraps were regarded as waste by the Turks and Kazak knowledge of the economic potential that lay within a scrap industry was the impetus for occupying this unexplored economic niche.

This leather industry generated a small-scale shift in the political and, to some degree, economic importance of areas settled by the Kazaks. In the Sultanhan settlement, economic benefit was shared by local Turks and the Kazak community provided an industry and employment for the underdeveloped area. Employment opportunities for locals was one outcome of the Kazak presence in the area as Turkish youths were hired by the Kazak community to collect hides from dealers in Istanbul and send them back to Sultanhanı. Before long the town of Sultanhanı's administrative status changed from kasaba (town) to merkez (center) and Svanberg, who spent a number of years with the Kazak community in Istanbul, gives credit to the Kazak presence.

New urgency to substantially increase their economic security emerged in the wake of new economic pressures. The completion of the power plant at Salihli, which had been a source of employment for many Salihli Kazaks, caused a reduction in income which significantly affected the community. Secondly, with the termination of the period of exemption from military service, many men were being called to service creating economic pressure on the community. In addition, loans granted for the building of houses and business investments were now coming to term. As a result of these pressures, the community need for decisive action in securing a secure and stable 
economy led to further investment in the leather industry. Furthermore, a community decision was made to relocate to Istanbul for greater employment opportunities in addition to reasons of proximity in order to cut transport costs associated with shipping leather scraps from Istanbul to the primary settlements. The 1961 Turkish Constitution played a role in the emigration of some Kazaks to Europe which led to greater financial inputs into the community through remittances. The move was made to Istanbul's Zeytinburnu neighborhood, an area already settled by some Xinjiang Kazak families, many of whom took advantage of the constitution's laxity on emigration and relocated to Germany. Their vacant houses became occupied by family members moving from the primary settlements and allowed them to avoid paying rents thus reducing their economic burdens.

The 1970s tourism initiatives in Turkey had direct benefits for the Kazaks. Istanbul's Kapalı Çarşı (Grand Bazaar), an enormous historic retail and wholesale bazaar housing goods from tourist wares to a thriving gold and jewelry market to textiles and artisanal goods, provided the venue for much of the success of Kazak leather products dubbed "Afghan coats" and "Afghan vests." Soon workshops were replaced by small factories and the Kazaks began to fill the economic niche left behind by the emigration of Jews and Greeks in the 1950s who had been the key stakeholders in the Istanbul leather industry. The movement from this traditional craft, as it has been called, to Kazak investment in the plastics industry was precipitated by a decrease in demand for Kazak leather products due to the over establishment of the market. The plastics companies that emerged in this era possessed almost exclusively Kazak shareholders and many companies were located in the same neighborhoods as the leather workshops. It is 
unclear from the current research as to the nature of the labor incorporated in their operations and much of it may well have been comprised of the local Turkish population.

The culture of the Zeytinburnu Kazaks provides an important contribution to their social operations. Leaders among the community were treated with respect and descent groups tended to continue to carry importance as a source of individual identity as well as demarcating the boundaries for acceptable marriage. Education was valued as an investment among the community and "if a father did not allow his daughter pursue education, he was negatively regarded" (Interviews with Abdülselam). Higher education was encouraged among many Kazak families. The Kazaks have not existed in cultural isolation despite their close ties. The combination of urbanization and increased integration as well as education opportunities have led to the development of more modern values in the Kazak community which is potentially due to the enclave effect.

On arrival to Turkey, the social organization of the Kazaks experienced a transformation from one governed by nomadic organizational structures to a more egalitarian organization. Nomadic culture was necessarily abandoned which undermined the organizational formations that legitimized the power base of nomadic leaders. The result was that all members of the community had to start from scratch and thus new ways of social organizing developed.

In the 1970s, the youth of the Kazak community became interested in their identity and background as Kazaks. Fed by pan-Turkist ideas to some degree, that is the nationalist idea that all Turkic peoples are of the same origins and share a common culture and language, the youth began to engage in the reproduction of cultural activities. These included an interest in the Kazak language, dances, history, textile arts and their 
political background. Out of this period came the idea that spatial self-segregation of the community was necessary in order to preserve their culture. This new neighborhood would be called Kazak Kent, or Kazak Town, and was a new development intended to increase the living standards and solidarity among the community.

The relative initial success of the Kazaks can be attributed to many factors. As refugees, they were prepared to adapt to a new life in Turkey, realizing that return to the homeland was an impossibility. The hardship endured by the community and their political engagement in their Xinjiang homeland provided them with a positive self-image that gave them confidence. They were welcomed by the Turkish state in a period of acceptance of Turkic immigrants and aided with tax breaks, housing, and other incentives and subsidies, as mentioned above, as well as assistance from the East Turkistani Kazak Refugees Association which gave them a solid footing in their new home. Traditional know-how became a crucial element to their success as "knowledge of how to prepare hides and leather was a cultural resource they could exploit in exile" (Svanberg, p 181). Their positive self-image was further reinforced by their economic success coupled with what they viewed as their heroic past and this positive self-identification has given them a sense of superiority. These aspects reflecting a culture of certain strength has no doubt been a "decisive factor in the persistence of the group" (Svanberg, p 184). The notion of community social organization offered by Sampson is relevant in this discussion. His analysis states that community social organizing is about the ability of a community to realize the common values of its residents and maintain effective social controls. This, he relates further, is the "capacity of a social unit to regulate itself according to desired principles, to realize, collective as opposed to forced, goals" (Sampson, p 167). The 
social controls he discusses are the positive regulatory forces of a community which enforce behaviors that are beneficial to itself and not defined as those associated with repression and forced conformity. This is of importance for the Kazak community in Istanbul because its ability to maintain such controls are essential for its survival. The degree to which these controls become too repressive and restrictive is the point at which community cohesion may begin to break down in light of other options in the greater urban "community." 


\section{Chapter IV. Community and Adaptation}

\section{Community Among the Kazaks and Positioning in the Modern Economy}

In defining the terms of community extant in the Kazak community it is useful to revisit the defining characteristics discussed by Daly and Cobb earlier. The first requirement is extensive participation by community members in the decisions by which life is governed. The second is the taking of responsibility for its members by the society. The last requirement is a respect for the diverse individuality of these members. The Kazak community engages in participatory practices in the form of general assemblies which are held particularly when visitors from Kazakstan are present to discuss cooperation between the community or its elites and the Kazak government on cultural issues and activities. Through the Kazak Turk Foundation, key community representatives have established a relationship with the government of Kazakstan and bridging events are organized between the two entities. The community or certain aspects of it engage in responsibility taking for other community members through the Kazak Turk Foundation, a cultural institution that facilitates social and cultural activities and is funded by donations, occasional funding from the government of Kazakhstan and other sources, and on an interpersonal level in times of hardship. For example, the Foundation offers assistance to those who need financial aid. Assistance is also supplied through the distribution of materials such as coal in the winter as well as through administrative support. Some evidence of respect for the diverse individuality of members, another requirement presented by Daly and Cobb, is reflected in a story told by the director of the Foundation about a community member who turned to drinking. The individual became a burden to himself and to the community but was apparently not 
ousted from the community. Later when the individual died of alcohol related illness, he was given a burial and the funeral was widely attended by the Kazak community who, despite his personal decline, paid their respects (Interviews with Abdülselam).

The community is able to realize many of its collective goals. They include its cultural and to some degree its business orientation towards Kazakhstan. The community is involved in joint activities with the Kazakhstan government that foster cultural and business linkages. In one cultural example, the Istanbul Kazaks send a team of young soccer players for matches with local teams in Kazakhstan every year so that young Istanbul Kazaks have a chance to interact with the country of their cultural origins if not the country of their territorial origins. These players are sponsored by the Kazak government as a sort of good faith gesture. Parallel to these activities, business activities are organized between the two countries with the Kazak community of Zeytinburnu acting as cultural ambassadors for events such as in the Turkey and Kazakhstan Business and Investment Forum held in Istanbul in 2009 (Interview with Abdülselam, 15-8-2011). Some community member claims that their presence has been and is a stimulus for closer partnerships between the Istanbul Greater Municipality and the government of Kazakhstan. The community's continued production of culturally based events within its own community as well as those for outsiders is another manifestation of its collective goals and involves the representation of the community to non-community members. This requires an awareness of what the community wishes to present to outsiders. The education of the young in the Kazak language and the encouragement and assistance of student community members with financial aid through the Foundation are based on cultural and economic goals that are intimately integrated in the community. The 
existence of the Foundation itself, the assistance of community members in need, the organization and provision for religious education, and the continuation of traditions unique to the community in collective venues such as marriage ceremonies are all additional manifestations of mobilization efforts from within the community.

As the community moved from a traditional economy of animal husbandry, and in this process from the tradition of transferring knowledge or metis to its younger generations, it entered into an economy organized according to commoditized relationships. A problematic question for the community would have at that time been how to maintain the community economy in this new and alien economic setting and thus maintain the bonds of community. This evokes Bourdieu's definition of social capital which involves the aggregation of resources linked to a durable network making the link between cohesive community and the mobilization of resources. The new economic activities were no longer the ones that required cultural and social relationships to carry them out. A new set of relations became necessary to articulate the community to a modern economy and the virtually free and limitless labor that could be garnered in the Altai Mountains in Xinjiang through the family economy was almost to be a thing of the past. In the early stages of the Kazak leather industry, however, both in the provinces where they were first settled and later in the Zeytinburnu neighborhood of Istanbul, a similar labor structure to that of their pastoral past was used based on family labor. Workshops were established in homes and women, men and children would work sometimes until late in the evening employing their labor power to create products for sale on the market for the good of the community economy. A system of production was employed wherein family members contributed their labor to a single task, the production 
of leather garments which involved the cutting and sewing of leather pieces. Much of this economic activity was technically informal where working hours and pay were both unregulated and may have even bore an exploitative dimension. It is, however, more likely that the community employed the same labor strategies that they used in the Altai Mountains which has been described by community members as inseparable from the community economy. This arrangement was discussed in terms of a community effort whereby members pulled their efforts collectively to realize greater returns for the benefit of the greater community (Interview with Abdulvahap Kılıç, 21-5-2011). Their pastoral labor strategies based on unvaluated labor were thus transplanted to their new economic situation.

In theoretical terms, at this point in the history of the Altai Kazaks in Turkey, the gains of their production were now becoming more and more abstracted. Instead of producing dairy products, meat and wool for direct consumption and use as they did in the Altai, they were producing to sell in order to buy the products they would consume (although it should be acknowledged that the Kazaks were also involved in trade on the Altai steppes). This abstraction of production, experienced within the first generation of migrants, began with collective leather companies with heads of families participating in joint ventures as shareholders and labor being provided along family lines. Companies later began to move to fewer partners or a single owner and after the move to Istanbul, labor was sought out from the city's greater labor market (Interview with Abdulvahap Kılıç, 21-5-2011). Thus the economy of the community was no longer community-based nor was community involvement in its processes completely necessary or desired. The input of community members would now flow out of the community and labor would no 
longer be a component that reproduced the culture tying the community together. The community, however, maintained a relatively good standard of living and many developed a measure of wealth. It was reported by community members that once wealth began to be attained, the community lost the need for community-based economic strategies. Company owners began to seek their labor from the greater labor pool. A possible explanation for this might be the lower costs in social relation terms and a greater amount of flexibility in hiring and firing practices. One explanation given was that community members did not want to work together once they began accumulating enough wealth to be independent from one another (Interview with Abdulvahap Kilıç, 21-5-2011). As an example of this Abdulvahap explains, "Some members of the community moved to other areas outside of the community. Some of the wealthy moved out to the location of Kazak Kent which is far from here" (Interview with Abdulvahap Kilıç, 21-5-2011).

\section{Adaptations Related to Culture}

The community was to face difficult times in the following decades of its history. Fortunes shifted as new entrants and economic and political forces weakened the community's economic vitality in the 1980s. Times became difficult in Turkey during the late 1970s and 1980s during the political constraints of the 1980 coup, when the country became polarized between right and left wing factions, and violence leading up to it. Shifts in demand also served to cripple the leather industry and plastic manufactories also suffered from foreign competition. These events strongly impacted the community. 
Cultural promotional activities now seem to be a significant part of the community's activities. The activity of community members in the promotion of the community's own culture through cultural fairs and community artisans who make culturally specific crafts may be interpreted as the community's attempt to secure its own validation and legitimacy through the emphasis of traditional aspects in its modern and urban environment. In the absence or loss of economic or real political power, the community may attempt to seek validation in other ways. The interest and acceptance of its culture by others may serve to strengthen its sense of self and may be an attempt at searching for its own identity in a context in which it is unable to affirm itself through its historically traditional practices such as horsemanship, the playing of kokbar - a rough game played on horseback with the object being to lift an emptied goat carcass off the ground and carry it around a white marker on the other side of a field while being pursued by eager fellow mounted players, an economy based on livestock all of which require space and a pastoral life. From the felt products made for sale at cultural events to the kind of cuisine of mutton and oily rice and meat dumplings and various dairy products to describe a few dishes particular to the community, these are remnants of a culture that developed its cultural identifiers for a very specific kind of lifestyle in a very specific environment. It is not surprising that the community is perhaps perpetually in the process of trying to make sense of itself and adapt where adaptation is needed and maintain other cultural aspects when it can. The loss of its traditional practices which are essential for their identity is widely felt among the first and second generations.

The community also has established links to the Republic of Kazakhstan. Out of these cultural and economic links, the community creates a living reason to continue to 
speak its native tongue. The stronger and the more intensified this link is made, the more reason and legitimacy the community will have to value its native language. The same is true for the production of cultural goods such as felted wall hangings, bags and other products. The creation of an internal and external demand (from pan-Turkist ideas of eastern Turks being the "original" Turks and the desire for modern Turks to possess symbols of this perceived cultural origin) for its cultural products gives the community reason to continue to produce these goods. In an active way, the community, or at least some of its members, is attempting to create demand for its culture. This may act as a propelling force for legitimating the community's existence with some of its culture intact. Desired by outsiders in an environment where it is the vast minority, the community can forget the question that must plague all ethnic enclaves at some point or another; Do we abandon who we believe we are and become part of the great majority, or do we have a reason to maintain our uniqueness in a way that is not a perpetual struggle? Through these means the activity of cultural reproduction becomes an activity of reduced effort and does not have to be forced. The pull becomes directed from an external source and provides an unbeatable motivation. This in turn may have positive consequences for the maintenance of its stock of cohesion and its internal as well as its possible social capital.

Back on the steppe in western China, the cultural adaptations made by the community were a part of its negotiation with its environment and the economy developed to fit that environment and its lifestyle choice. Transportation on horseback in an infrastructureless, open landscape, subsistence primarily on meat and dairy products due to higher altitude and semi-nomadic lifestyle, and economy based on these products 
and the trading and selling of livestock, especially horses and sheep, for its external needs. These are all components that contribute to the types of goods the community produces for its own consumption such as felt boots, wall hangings, floor covers and yurt coverings, leather boots, coats saddles and other trappings. Transportable yurts are important for a transient lifestyle. Woven and felted furnishings were used for their ease of transport. A unique culture formed around wool and its uses and this plentiful resource had become the answer to many of the needs of its community. The community's culture and identity were driven by the foundations of its economy as an integral part of place and its manner of organization. Taken out of that setting, the cultural fabric of the community has less hold and its form begins to morph into a less organic entity.

In some form, it seems that some elements of the Kazak community have sought out its own culture as the answer to the potentially destabilizing forces of the modern economy to keep its community together. While the invasion of cheaper imported goods has struck a blow to the community's economic base, the use of culture, or the reliance on culture to attempt to maintain a cohesive community and strengthen its more binding identity symbols such as language and the production of certain cultural items has been a powerful tool (Nur, Şirzat Interviews). It is perhaps the case that because a strong culture and identity already existed in this community that they are more resilient to the global economy's potentially debilitating effects. Evidence from this study, however, suggests that there is an active use of culture to promote the community by a few actors returning to culturally oriented enterprises which may in turn give the community reinforcement against the misfortunes of participation in the global economy. This use of culture may 
be an unconscious response to economic difficulty that really attempts to focus more on community building or vague regrouping through cultural validation.

It may be and is sometimes argued that community members experience greater gains by not participating in the community. Certain practices and social obligations may be obstacles to personal advancement. These may include the high cost of marriage since the groom's family is required to provide a meal for hundreds and maybe even thousands of friends and relatives. There is the cost of non-anonymity. Anonymity can bring great personal freedom and reduce responsibility for one's actions. It may also eliminate the transaction cost of reciprocity. If relationships are weak and non-binding then one can act without being bound to repay a service in kind. One is free from tightly binding social obligations and can maneuver more flexibly through the field of social relations relatively free of stigma for behavior deemed deviant by one's community.

These may provide benefits to individuals, however, the costs to community associated with this kind of individualism are significant. One result indicated by Putnam is that personal goods and private initiative become more important than shared public concerns (p. 259). Levels of well-being are said to decline with runaway individualism and Kazak youth are becoming more isolated from family and even friends as they succumb to the demands of Turkish culture (Zeytinburnu Municipal Cultural Events Manager, 25-11-2011). Putnam notes that every generation after the 1940s in the U.S. shows a higher level of depression starting earlier and earlier which is correlated with the decline of social capital and the increase in individualism. Freedom from reciprocity may feel liberating, however, reciprocity is essential for maintaining the social fabric.

Gouldner states that: 
... if the gratification of either party's needs is not contingent upon the other's reactions, the stability of their relation is undermined. This, in turn, implies that if a social system is to be stable there must always be some "mutuality of gratification." Social system stability, then, presumably depends in part on the mutually contingent exchange of gratifications, that is, on reciprocity as exchange. (Gouldner, p. 13).

Trust becomes a casualty when there exists a dearth of reciprocity. Freedom from reciprocity means that there are less consequences for one's actions but this is extended to every individual and under these circumstances the consequence free life fades into myth.

The value of reciprocally-based social practices extend beyond their material costs. The small wedding party may be less costly and allow more people to marry more freely, but they also marry in smaller and smaller communities within smaller and smaller circles thus slowly reducing their social networks. This may narrow the social sphere of community members until a community begins to fragment into smaller and smaller units. Social atomization is a potential risk in the loosening of social obligations and this has a weakening effect on social capital and henceforth a community's ability to mobilize and realize its collective and shared goals.

As I observed, traditional marriage ceremonies are maintained in their traditional form in the Kazak community. This appears to be a practice that is still a necessary and important part of the community's culture and the traditional meal of mutton with rice is served to large groups of men and women who dine separately while sitting on the floor. It still serves as an important venue for social contact between members of the community. 


\section{Embeddedness and the Moral Economy among the Kazaks}

\section{Moral Economy among the Kazaks?}

Community is present when a vital social fabric exists in a place. This is the soil in which morally based relationships are able to function. Social relationships are loaded with built-in obligations. This is the embeddedness of economy or rather the embeddedness of responsibility that underlies social relationships in such close-knit communities. Whether in Scott's South East Asia where wealthy villagers and landowners are obligated to provide assistance to their less fortunate compatriots in times of dearth or in the Kazak community of Zeytinburnu where support is provided through the Kazak Turk Foundation (Kazak Türkleri Vakfi), a primarily cultural institution that operates as a central organizing hub for community affairs and activities, as a mediator between the wealthier members and the less well-off ones, the situations are similar in that the economy is to some extent built-in to existing social relationships.

To take a step back, let's look at the neighborhood of Zeytinburnu itself. It is an older Istanbul neighborhood on the outskirts of the old Byzantine walls with very little left standing of any age. Most of its buildings were built from the 1950s or so and up with most being more recently constructed. Residential is mixed with commercial and most buildings are five story concrete structures. There is a broad main commercial street that runs through the neighborhood and serves as its main throughway. The population is mixed and made up of primarily Kurds, Mongolians, Uzbeks, Kyrgyz, Uyghurs, Turkmen, Afghans, Turks, and of course the Kazaks which have a population of around 12,000 . It is mainly working class neighborhood with many entrepreneurs. The feel is conservative and individual-based violence occasionally erupts between the 
Kurdish and Central Asian residents. It is in this context that Foundation operates as a tool for distinguishing and affirming Kazak culture and a cohesion.

The Foundation serves the function of a service provider mediating between wealthier elements on the one side and less fortunate segments of society on the other. . The Foundation's economic function is to assist and supplement incomes through very modest subsidies when times are hard. It does not have the capacity to serve as a job provider or bear complete responsibility for lower income earning members in the same way that wealthy landowners did in Scott's S.E. Asia or wealthier herders in the Kazak community in their pastoral homeland. Rather it provides a last resort support for those who have either exhausted the resources of their closest relatives and friends or for those who do not have any other means of support. These financial support activities to some extent replace the previously embedded responsibilities of the wealthy to the poor in the community, particularly in their pastoral context in western China.

Kazak nomadic social organization was similar to that of a group of nomadic Kyrgyz who immigrated to Turkey in the 1980s due to political shifts in Afghanistan where they lived in the Wakhan Corridor between Pakistan, Tajikistan and the Eastern Turkistan (Xinjiang) region of China. They possessed a system of inclusiveness that found ways to shift resources to poorer community members to provide them with a means of subsistence and activities that gave-allowed them to participate to a greater capacity in the main economy and cultural operations of the community. Among the Wakhan Kyrgyz, when a member of the community was too poor and did not own his own sheep, the khan, or leader, would provide him with a number of sheep from his own flocks. The receiver was to act as a caretaker of the sheep which would still remain as 
the khan's property. The caretaker might live quite a distance away on horseback from the khan's own camp. He had the right to use all the products of the sheep such as milk and wool but had to keep the sheep healthy and could not allow an unacceptable number of sheep to die unless circumstances were extreme. If found guilty of neglect or laziness, the caretaker would confiscate the sheep that were given to him and give them to another family. If he had done well and most or all of the sheep were healthy he may receive more sheep to look after or may be given a number of sheep as his property by which means he could increase his wealth. He might be allowed to keep healthy offspring and thus increase his wealth this way in addition to benefiting from sheep products like the milk and wool (Interviews in Ulupamir, 2006). The Kazaks had a similar feudal-style system for its poorer members that operated much in the way described above (Benson, 1980).

Such a system ensured that every member had a place and that everyone could participate. In effect, the less well-off had the occasional role of tending to or acting as the caretakers of the surplus of the more well-to-do. By tending to this surplus, which the wealthy owner does not have the capacity or resources to look after, the less fortunate of the community could directly benefit. They are permitted to keep some of the profits of production without having to have made any capital investment. The community ensures its security by preventing the development of rogue members whose only recourse might be to raid and steal from other members and cause disruption and instability perhaps gathering followers along the way causing instability (Evans, p. 9). In the case of such a situation, their legitimacy may find increase until they become a powerful enough threat to the original community. But if prevented through the redistribution of surplus, their 
worth becomes validated through the performance of functions central to the culture of the community. They are prevented from slipping too far below acceptable limits of poverty, their "right to subsistence" is looked after and respected and they are affirmed by the community as having a place in the society. The more wealthy bear out their responsibility to mobilize their excess wealth to legitimize this place and to ensure a healthy community and society in exchange for status. This type of welfare arrangement has an overwhelmingly practical aspect that bears an important social function as "many Kazaks from the community visit the Foundation" or attend its events (Zeytinburnu Municipal Cultural Events Manager, 25-11-2011).

Being that the Kazaks indeed had a similar system in the pastures of Xinjiang, the Foundation may be interpreted as its modern, urban version. Unable to go to the extent of being able to redistribute excess wealth to validate place in society through some donations from relatively wealthy community members, to ensure a certain level of subsistence, and to provide culturally meaningful activities, the Foundation resembles a pared down form of the redistributive system of the pastures. With a drastic change in the community's means of production, its ability to control the processes of production has become weakened and vulnerable to distant economies. Competition is a crucial component to survival in the very rough economic context of Istanbul where external pressures and economic actors are major threats to the community economy whereas allies, support, and healthy numbers with a minimum standard of means and capacity have been seemingly more important concerns in the pastures, where the community was largely internally focused and where the materials necessary for maintaining livelihoods were produced internally and free from competition. Furthermore, the immediacy of 
having to take care of a downtrodden community member for the preservation of the community as a whole was likely a strong motivator for moral social action (Polanyi, Scott). More than likely, one way or another, a destitute member of the society would have to be dealt with either after the member has sunk far into destitution or preventatively whereby he requires less resources and little or no conflict to pull him out of destitution. The Kazak Foundation has taken on a responsibility of a moral nature in its assistance to the poorer members of the community with what modest assistance it is able to provide. It is, in essence, an institutional manifestation of a social structure that ensures the survival of the community as a greater whole by protecting its poor from declining to a dangerously low economic level. This is not to take a utopian view of the community's pastoral past. On the contrary, it is an attempt to understand the social factors that differentiate the pastoral economy from the urban one. The forms differ between the two settings. Where there are always the poor and vulnerable, the method for assistance have changed from one of providing assets for a vulnerable family to build or rebuild a stock of assets, in the pastoral case sheep, to one of handouts that do not have any specific asset building quality. In the commodified environment of the city, asset building opportunities to alleviate poverty may be harder to come by.

In addition to this function, the Foundation provides a marginal space or a third space for networks to form through cultural activities or visits with fellow community members. It provides a place where news is inevitably passed through the community. As a viaduct for the sharing of information, the community is able to pass on information which may be beneficial to other community members. The Foundation acts as a supplementary resource for the facilitation of work or other economic opportunities. 
Outsiders at times visit the Foundation and use the space to visit with friends from the Kazak community. This use of this public space inevitably serves to expand networks and bring community outsiders and insiders in greater contact with one another. The casual setting may facilitate unexpected economic opportunities. From a moral economy perspective, this third space/marginal space function of the Foundation can be equated to a degree to the marginal lands of peasant subsistence farmers. As discussed by Scott, these were lands such as forests and natural fisheries that peasant farmers could use to supplement their incomes (Scott, 1976, p. 63). They functioned as a public good that all community members had a right to access and provided services that permitted greater independence and the ability to sustain in times of low crop yield. The Foundation, although not providing continual economic supplementation, may be interpreted as a similar marginal resource in a tight economic framework with limited horizontal movement based solely on the income of wages where pastoral and rural communities would typically have a diversity of subsistence means. It may be a place created by the community to carve out some means of horizontal mobility, as a space that offers some reprieve in a tight economic system. The uses are similar.

The community in Zeytinburnu has other avenues of financial support for its most important customs and traditions. Weddings, death and circumcision are the main events that are supported by this community fund. This tradition is observed by the separate Kazak clans within the community and money is collected over time by one member of that clan who keeps it until the day it is needed (Interview with Zeytinburnu Municipal Cultural Events Manager, 25/11/2011). The core of this practice is the collective responsibility of the clan for the traditions that enable it to continue. 
In the case of the loss of a job, a home, or inability to pay bills, the community is able to mobilize to assist those members who require assistance through the Foundation. The manager of the Foundation, Abdülselam, relates incidents of community members in financial difficulty and in need of serious assistance. One incident involved the loss of a community member's home. Abdülselam tells the story of how the Foundation was able to mobilize the community to make contributions to save the home. The Foundation also assists families with financial problems by first digging into its own resources. When this proves insufficient, the Foundation calls on community members and business owners to supplement assistance. Poorer community members are often provided with coal in the winter for heating. During Ramadan, the month long period of fasting, less prosperous families are traditionally supplied with lamb and cow meat. This meat is traditionally redistributed to poorer members of the Muslim community. The Foundation has also assisted visiting Kazaks who lose their money or end up in difficult financial situations. Thus, their redistribution and assistance activities extend beyond the immediate community (Interview with Abdülselam, 4/5/2011).

Student assistance is also a duty carried out by the Foundation. They are able to provide 14 students with financial aid to study. Their contribution amounts to 100 Turkish Lira (around \$60) a month. There are around 500 Kazak students currently attending university - both boys and girls seem to be encouraged with girls putting off marriage after the age of 25 to study (Svanberg, p. 139) - and so the assistance the Foundation is able to provide is minor in comparison to the need. They are, however, at times able to secure additional funding for students. In one such case they were able to procure a grant of $\$ 25,000$ from the Kazak government. The money was initially offered 
to the community for other purposes and the deal was on the verge of falling through when the Foundation mobilized to secure the funding and subsequently redistributed it for education assistance.

There is evidence that assistance also comes from Kazak firms. In an interview with Abdulvahap, a producer of plastics products for construction such as insulation and jacketing for construction applications, it was indicated that Kazak companies provide monetary assistance to the community or community members when needed. This system appears to be informal like many of the community's other redistribution practices and so it is difficult to determine how significant a factor these companies are in assisting those in need (Interview with Abdülselam, 4/5/2011).

In an active way, the Foundation reflects Scott's much discussed notion of a moral component as part of a society's functions. Communal structures are often more able to redistribute pain to avoid or postpone crisis (Scott, 1976, p. 203) and the Foundation may carry out enough communally based action to do this. Although the community was not organized around agricultural activities, the existence of the Foundation and its capacity for assistance of community members as well as the previously collective nature of Kazak manufacturing firms indicates the prior existence of a moral community and a continued ability to implement it. The community's recognition that it is a necessary aspect of a functioning community is significant when state structures might make such a component of the community obsolete. This institution, however, operates where state institutions cannot and has direct significance for the meaning of community which state institutions of assistance do not. If not for the Foundation, the nature of the discussion of community within the Kazaks would likely be 
much different and the notion of community for the Kazaks would likely be more difficult to locate. 


\section{Chapter V. The Ethnic Enclave in the Kazak Context}

\section{Economic Development and Social Aspects of the Enclave Economy}

The Istanbul Kazak community in many ways fits the ethnic entrepreneur model as discussed by Aldrich and Waldinger, and Sanders and Nee. Three factors are important for the success of the ethnic enterprise. These are defined as opportunity structures, which consist of market conditions that may favor products and services demanded by co-ethnics, group characteristics, which include prior factors such as selective migration, the group's culture and levels of aspiration, and finally ethnic strategies, which are described as emerging from the interaction between opportunities and group characteristics, as the ethnic group adapts to its new environment. The type of environment that can support the emerging immigrant entrepreneur is of particular concern to researchers. Aldrich and Waldinger (1990) outline four circumstances for which their enterprises are more likely to grow in the open market: unobserved or abandoned markets, enterprises characterized by small economies of scale, in markets with unstable or uncertain demand, and in markets for exotic goods. The case of the Kazak community in Istanbul supports each of these four factors as evidenced by preceding discussions above. They took up an abandoned niche, possessed enterprises with small economies of scale, demand was initially high however, as their enterprises grew relatively rapidly it appears that demand and stability both grew up to a certain point of market saturation (Svanberg, 1989). Finally, the leather goods they produced had a market among hippies of the time. Group aspirations dictated an entrepreneurial approach to earning a livelihood stemming from a life of relative freedom in the pasturelands of the Altai where families tended their own flocks. 
Where both owners and workers are of the same ethnic background, the enclave model applies. The benefits of the enclave economy to entrepreneurs has been described as comparable to that of entrepreneurs on the open market but some research brings into question the benefits for co-ethnic workers who may see fewer returns to human capital than if they were selling their labor on the open market (Sanders and Nee, 1987). In some cases, co-ethnic enclave workers may labor in sweatshop-like conditions enforced by ethnic solidarity. This may have been the cost of segregation and the Istanbul Kazaks' move to establish their own neighborhood may have been driven by desires of the Kazak elite to maintain an easily manipulated labor pool; however, there is no conclusive evidence that this was the case and they continued to benefit from maintaining close ties in multiple ways, particularly in an ultra-nationalist context in Turkey where they may be considered Turkic and even as "original Turks" but perhaps never really Turkish and thus always outsiders. Suspicion of the community as potential communists was a factor in the 70 s and early 80 s for their close ties to one another and group solidarity. The discourses of some elite community members reveal a narrative of individual input for the greater good of the community economy despite painstaking sacrifices in terms of long working hours. Another factor is the common experience of their migration and the difficulties endured on the voyage. This is reported among community members to have had a galvanizing effect on the community. The Zeytinburnu Municipal Cultural Events Manager has stated that one benefit "of continuing the community is to honor its pains."

Data regarding the economic standing of the community shows results supportive of the working thesis of this study about the relationship between strong cohesion and 
economic prosperity as well as its inverse. As the community's economic fortunes began to increase, some members of the community out migrated to an extent but the community remained strongly cohesive based on reports from respondents. This generation, however, is the migration generation and the one immediately following. These generations are more likely to be the most cohesive in any circumstances due to having lived difficult experiences and to their generational proximity to those experiences. Once the fortunes of the community took a turn for the worse, the community began to show signs of weakened cohesion. This is in the current generation after major assimilation affects have taken their toll. It is speculation to say that the cohesiveness of the community would be stronger today if its economy provided strong incentives for continued individual participation in its functions.

Earnings among the Kazaks in the earlier years of the previous decade (20002010) based on a quantitative socio-economic study in 2002 were lower than expected. Out of a sample size of 172 respondents, $65.2 \%$ male and $34.9 \%$ female, $20.3 \%$ reported earning 100 - 249 YTL (New Turkish Lira), 37.2\% reported earning 250 - 499 YTL, 29.1\% earned 500 - 999 YTL, and 7.6\% reported earning 1,000 - 2,000 and above (Çiğdem, p. 86) (see Table 1). The minimum wage for an individual in 2002 was 250.87 YTL (Özgün Ekonomi ve Makale Arşivi). To offer a measure of comparison, around the same year, spacious $90 \mathrm{~m}^{2}$ two bedroom apartments in the center of town (Taksim area) were renting for 700 YTL to 1000 YTL with apartments in less central areas being much cheaper. The World Socialist Web Site reported the poverty line in Turkey as being 1,600 YTL a month for a family of four in 2005 leaving a significant discrepancy 
between wages reported by the Kazaks and the income required to stay afloat assuming little change in the average community member's economic fortunes from 2002.

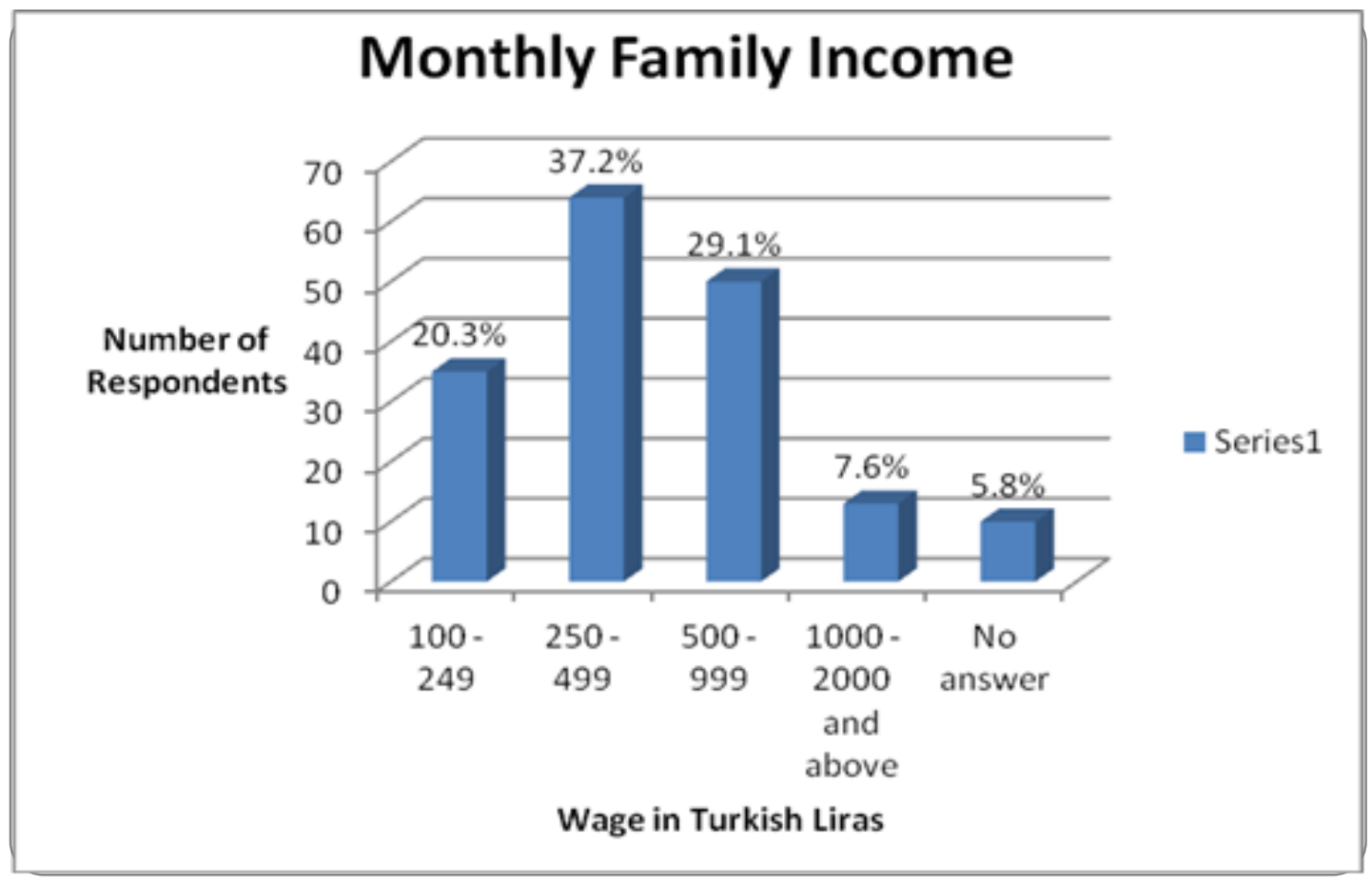

\section{Table 5: Monthly family income}

Only 17 of respondents reported additional income from interest, rents and/or land while $50 \%$ reported no supplementary income and $32.6 \%$ provided no answer (Çiğdem, p. 84). Sixty three percent reported being home owners while $30.8 \%$ were renters and another $6.4 \%$ were staying with relatives. The vast majority, $87.2 \%$, were apartment dwellers either renting or owning their residences. With $57.5 \%$ of respondents earning below minimum wage, an earning many times below the poverty line for a family of four, the community appears relatively hard pressed. With $62.8 \%$ of respondents living in homes that they own, many below poverty line income earners will have experienced some degree of economic security from not having to pay rent but still earn little and may 
find it difficult to support a family. Given this data, the community does not appear as prosperous today as in the 1980s when visited by Svanberg. Field observations, however, suggest very little if any real destitution. There was no visible poverty in the community. Buildings were well maintained and no applicants for assistance were observed on my many visits to the Foundation. This is certainly not a slum by any means. Poverty may be difficult to observe and may express itself it ways that are not always immediately apparent, however, the community, although struggling as some segments of it may be, a certain minimum level of financial security was observed. No great wealth, on the other hand, was observed either and the neighborhood very much resembles a working class neighborhood.

It is the general perception that the Kazak community is quite well off especially in comparison with Uyghur and Turkmen communities and impressions from other Central Asian Zeytinburnu residents of the economic position of the Kazaks will be noted here. A Turkmen informant causally commented on the very good economic standing of the Kazak community when it was mentioned to him that the community was under financial stress. Members of the Uyghur Turkic community also express a similar opinion as related from a fellow researcher working with this community. The perception of relative economic success from other Central Asian community members may provide more insight into the difficulties faced by these communities as opposed to the Kazaks themselves. Economic assistance from the government of Kazakhstan was mentioned by some Uyghurs as being an advantage for their economic standing.

Community members interviewed indicate that the economic situation of the community as a whole is not very good and that the situation had been better in the 1970s 
and 80s. Respondents complained of a stuck economy in which their businesses and factories in the plastics sector were shut down due to lack of orders. Plastics factory owners indicated that the cause was due to the importation of cheap Chinese products. The first quarter of 2011 indicated that Saudi Arabia with 81,780 tons, Iran with 33,723 tons and Belgium with 27, 978 tons were the largest exporters of plastics to Turkey (Plastics Today). These players may have had a more serious impact on the Kazak economy. It seems that whatever was left of the Kazak leather industry was mortally affected in 2007 by cheap Chinese imports as well as those from Kazakhstan who also started to produce cheaper leather goods (Interview with Abdulvahap Kıliç, 21/5/2011).

This scenario is complicated by other reports of lack of capacity from within the community to maintain a good business environment and to adapt to changing trends. One respondent related the decline of the community's economy to its own undoing. During the peak of the leather industry in the 1970s, Kazak dealers apparently sold their wares at inflated prices to Soviet Bloc countries and other European buyers: “The community leather producers harmed themselves by using deceitful business practices," (Interview with Zeytinburnu Municipal Cultural Events Manager, 25/11/2011). This served to severely damage the trust of clients and eventually caused irreparable harm to the sector. The sector later went bankrupt in the 1980s due to changes in the market and technologies as well as bad business choices. The community was unable to keep up with these changes and fell behind. Compounding the problem was a lack of education and it is believed by some community members that a stronger foundation and investment in education would have allowed the community to compensate for these 
shocks and setbacks and provided fuel for innovation (Interview with Zeytinburnu Municipal Cultural Events Manager, 25/11/2011).

In addition, employment in the community is highest in the leather and plastics industries. This is and remains the community's largest employer. The stagnation in these sectors means that the community will be hit disproportionately hard by circumstances affecting these sectors. The community has relatively little income diversity with 25\% (Other Careers and Private Sector) earning their income from other sectors (see Table 2, Çiğdem, p. 61). This data correlates with Kazak reports of a slow community economy.

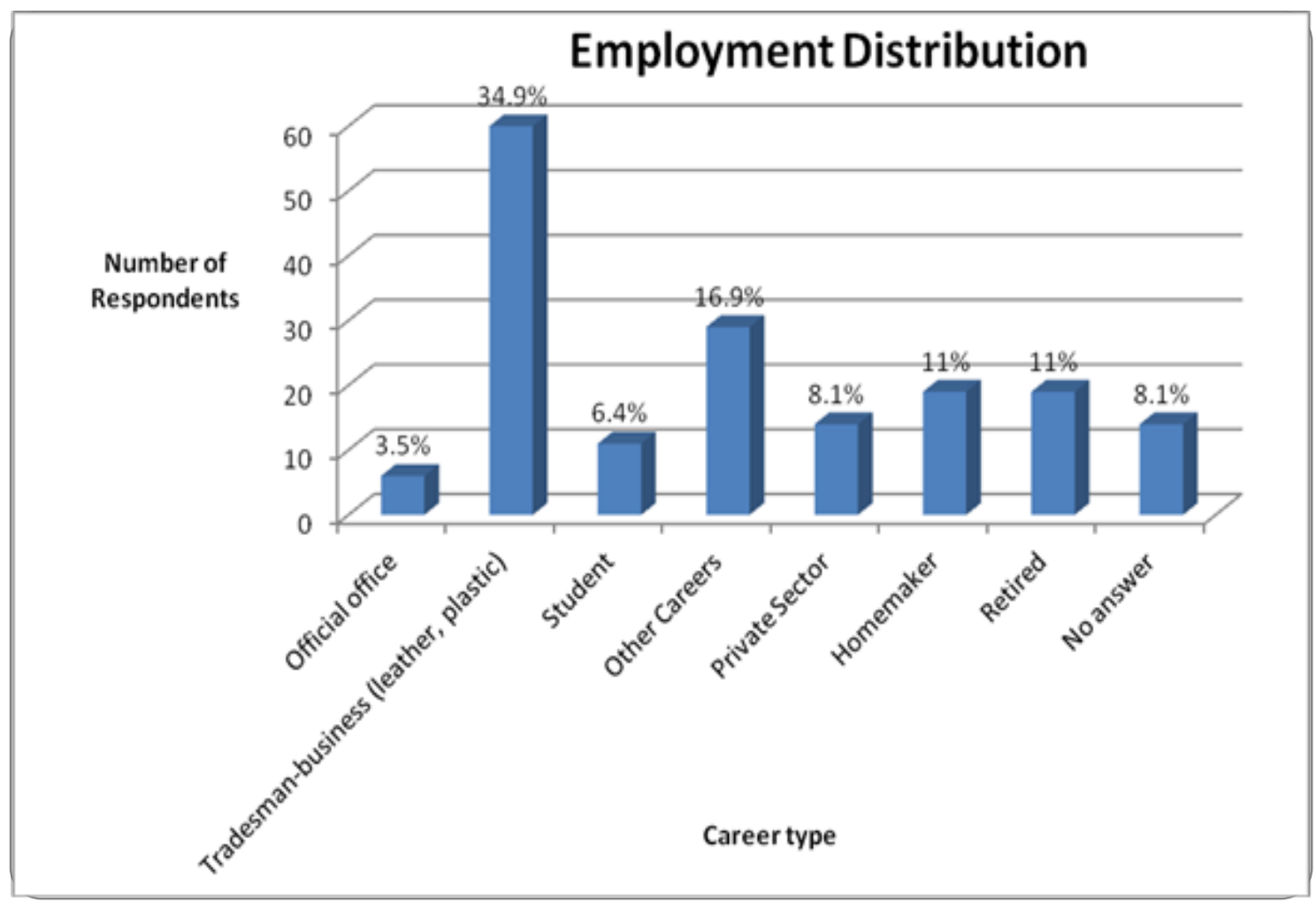

Table 6: Employment distribution 


\section{Kazak Firm Organization}

The early organization of Kazak leather manufacturing firms indicates a structure very close to the social organization of the nomadic community and an innovation to business organization unique to this community's experience. Firms were organized along tribal communal organizational lines with an aksakal, or an elder, as the "CEO" and a committee of investors and business men from the community who had varying ownership and shares of the company. Decision making was apparently organized in a council format and decisions were made through discussion with the decision of the aksakal as the representative decision of the council and the company as would have been the case at traditional community councils. This style of organization was later abandoned due to short-term demands for returns on investments by stakeholders: "Community members who invested in these companies came to early to demand their profits. They company hadn't had time to mature its profits yet" (Interview with Şirzat Doğru, 06/18/2011). Limited companies became the preference for companies because of their comparative ease of operation although they carried an increased risk as financial risk was shared by fewer actors.

Such vulnerability may be more easily absorbed where firms are operated by single owners in a community context. Where risks are more greatly shared, more contributors are likely to be adversely affected and in the case of an international competitor or competitors, there may be little in the way of collective support when the resources of all actors are taxed to the limit. In a situation where single ownership is the mode of operation, there may be a tendency for greater economic flexibility at the community level with individual members able to compensate for losses from its main 
industries and to support those facing difficulty by using resources from other revenue streams. It may make more sense for such community enterprises to remain atomized in an atomized economy where there are fewer and fewer protective barriers for producers of finished products. The consequences for collective firms may be community-wide economic havoc. This notion was reflected in interviews with Foundation Manager Abdülselam and Foundation Chairman Abdulvahap. They both noted that if they had emphasized education more strongly as a community, they would be in a stronger economic position today. This insight is evidence of the recognition of an atomized economic structure where personal investments in human capital are advantageous for the securing of better livelihoods The community can remain economically strong not only through community mobilization in the economic realm but by individual enhancements which are likely to benefit the community as a whole. If this is coupled with the greater self-awareness that education brings, as discussed by some community members, then cultural traditions that maintain community cohesion can continue to be observed in a more purposeful way. 


\section{Chapter VI. Social Cohesion and Capital in Zeytinburnu: The Stuff of Strong Communities}

\section{The Nature of Social Capital and Cohesion in the Kazak Community}

In this section, I would like begin with an overview of what the structures of social capital and cohesion look like in the Kazak community today. Putnam simply defines social capital as connections among individuals (p. 19). These are further broken down into bridging and bonding forms. A general overview of the Kazak community from what could be discerned from interviews with respondents in Zeytinburnu would present a scenario heavy with the bonding type of capital in the older generations where many wealthier members of the community have moved out to other neighborhoods with some wealthier community members having stayed behind to maintain their strong community ties and culture. The community's relatively closed nature is a likely strength and barrier to the qualities of its social capital. It has maintained strong inner connectivity that has kept the community cohesive while fostering external linkages through the Foundation with some individuals creating bridges between the community and external structures such as to local government and to the government of Kazakhstan. The external linkages it has created, bridging social capital, are, however, significant. They are links to foreign governments, local government structures and local and international business opportunities.

As the most recent since Svanberg's study and as the only quantitative study available we will examine the nature of some of the bonding forms of capital in the community through the data presented by Çiğdem. The quality of connections among individuals is an important addition to Putnam's definition of social capital. We have 
seen the table below in the Case Background section of this paper and it is useful to look at some of its implications for cohesion in the community. As an indicator of the quality of relationships between parents and children in a culture that values its community identity the following table shows the general respect that each seems to have for the other in marriage decisions (Çiğdem, p. 63). The data indicates a quality of negotiation that is suggestive of respectful attitudes to the wishes of both parents and their children.

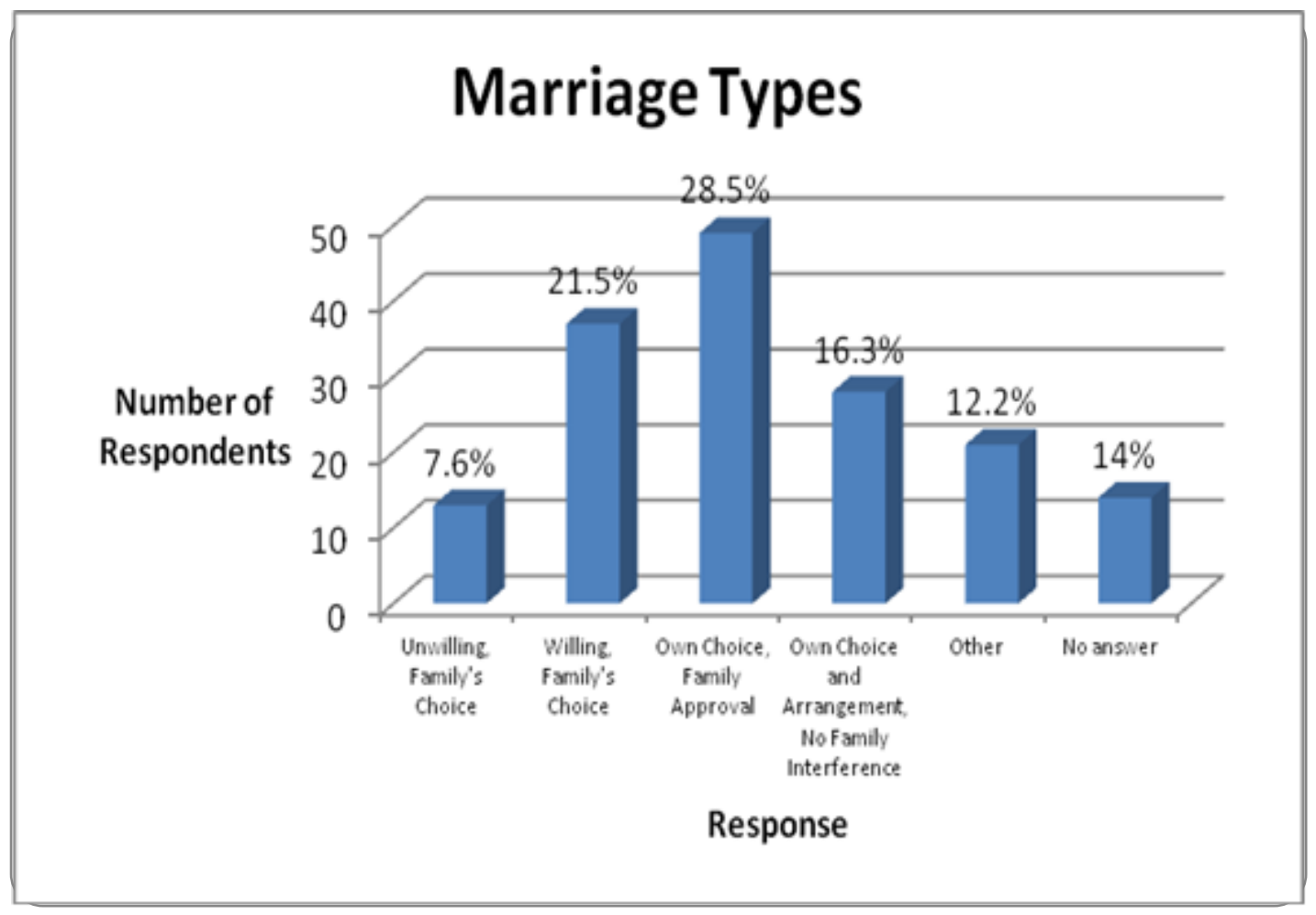

\section{Table 1: Marriage Types}

The total of those who unequivocally make their own marriage decisions is $44.8 \%$ with an additional $21.5 \%$ who are in the "Willing, Family's Choice" category. Some in this latter category may be under pressure to marry their parent's choice while others may conform to the tradition of submitting to the parent's choice while acting complicitly in the selection process. The semblance of parent's choice in these cases is performed to 
adhere to conventions of respect for one's elders, a value observed in the community. In addition to the data in the table presented here, $54.1 \%$ of parents said they would accept their child's decision to marry a non-Kazak while $28.5 \%$ were unsure and $13.4 \%$ being against (Çiğdem, p. 67). This may be indicative of a change in the community towards more assimilation. Acceptance for marrying outside the community was also something community members indicated was prevalent (Zeytinburnu Municipal Cultural Events Manager; Abdülselam Malkoç, Interviews). The significant portion of parents who accept their child's choice in marriage indicates a noteworthy level of trust in their children's decision making abilities and decisions themselves reflecting a higher quality of relationships in the community.

The amount of time community members spend with one another is also indicative of the level of social capital that circulates in a community.

\section{Frequency of Visits with Fellow Countrymen}

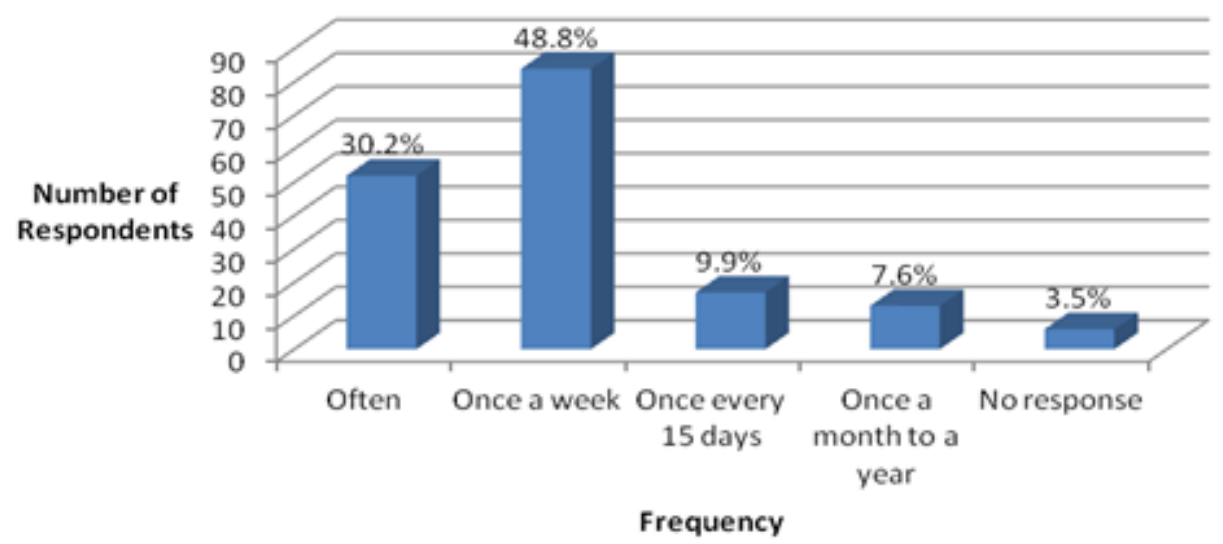

\section{Table 2: Frequency of visits with fellow countrymen}

This data infers a strong bond and close connection between community members with $79 \%$ visiting one another once a week or more. It does not indicate the nature of these 
visits or the duration, however. Putnam also indicates that the frequency of visits community members engage in is an important factor for determining the degree of social capital present in a community (Çiğdem, p. 70). When accompanying Abdülselam on errands on one visit to Zeytinburnu and on other visits, most of his drop-ins were on other Kazaks. He was known by Turks in the community but the overwhelming visits he made were to other Kazaks. Other Kazaks who came to the Foundation reported having many friends outside the community and one such individual visited the Foundation with a close Turkish friend who identified on some level with the Kazak community and felt himself somehow accepted and very well trusted by Kazak community members. One had the sense that he was almost "going native" in the manner of his closeness with his Kazak friends. These observations are mostly anecdotal but provide some indication of the validity of Çiğgem's findings.

Strong preference for social cohesiveness is the factor indicated by community members as the most important one for the community's urban integration. The majority of community members reported "Strong family ties" as the most important requirement for success in urban living indicating a focus on community cohesion and bonding kinds of relationships. This finding bore itself out in data on trust in the community where $62.2 \%$ of respondents indicated that they would turn to family members first in times of need (Çiğdem, p. 90) and such strong internal links are vital for the cohesion of the community. Based on this data, family structures appear strong while links across families within the community are well maintained making for a tightly-knit social fabric at the time of Çiğdem's study. The bonding character of the response "Transfer of culture to children" also rated high at $44.8 \%$ which, of course, has a high positive 
consequence for cohesion in the community. This value also seems to be currently upheld based on interviews with almost all respondents as well as evidenced from the Foundations activities webpage. The Zeytinburnu Municipal Cultural Events Manager mentioned the importance of "knowing one's origins" as one of the benefits of maintaining the community. Other community members, however indicated that the community was no longer distinct. On this issue Abdulvahap strongly stated that "the traditional community doesn’t exist anymore” (Abdulvahap Kılıç, 21-5-2011) indicating that although some forms of cohesion still exist and there are significant efforts to maintain this cohesion, they are in the face of a disappearing notion of community.

\section{Requirements for Success in Urban Living}

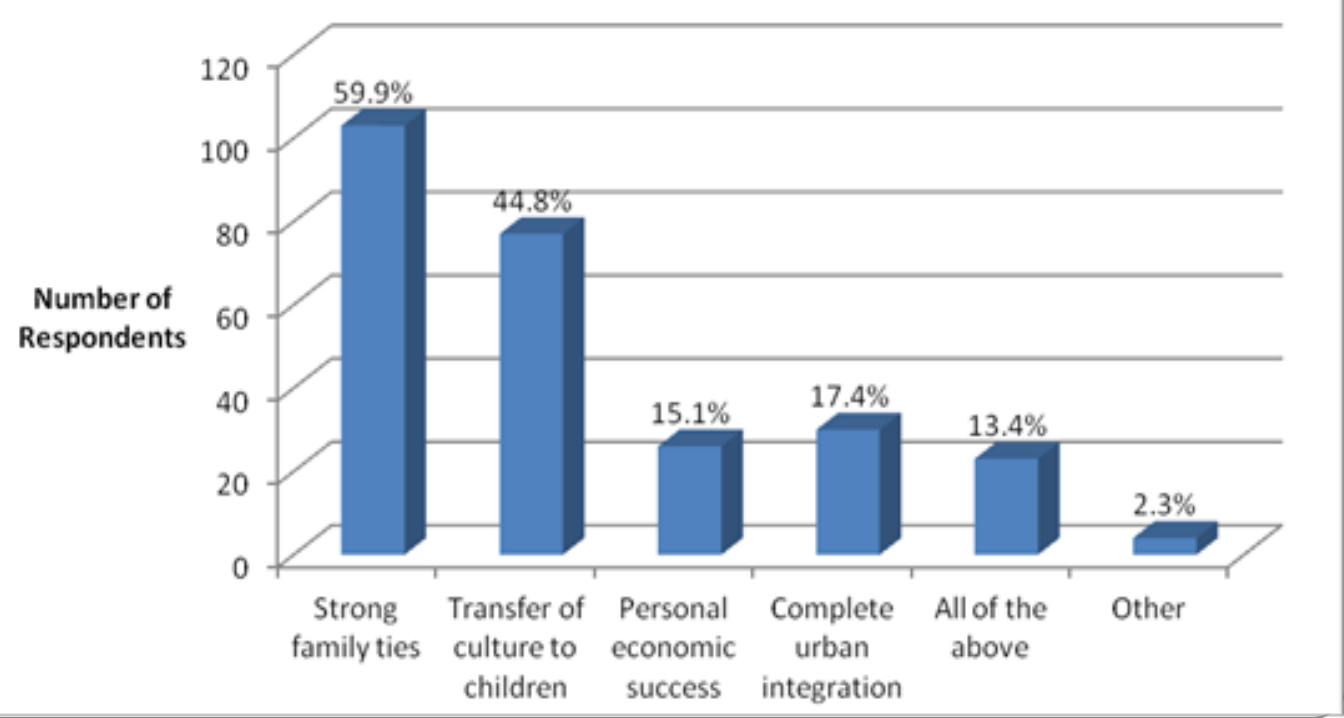

\section{Table 3: Requirements for success in urban living}

These indicators of community social capital are also indicators of the level of cohesion in the community. The ways marriage partners are chosen, the frequency with which community members spend time with one another and the most important factor 
for success in a highly anonymous urban environment being "sticking together" reflect the connections among individuals in the community that keep it together. These are the inwardly and horizontally oriented fibers of the community. While there are clear signs that the community's social fabric is weakening, there are also signs that social cohesion is relatively strong or there are at least very strongly motivated attempts to maintain cohesion such as through the values of imparting Kazak culture and Islam as a function of Kazak identity to the young, cultural activities through the Foundation, the Foundation's language courses, and the Foundation's links to Kazakstan to create a bridge to its "original" culture. The next section will discuss the Foundation and the specific role it plays in bonding members of the community through culture as well as linking it to external actors through its bridging activities.

\section{The Kazak Turk Foundation and its Role in Fostering Social Capital}

The community's main institution is its foundation, the Kazak Turk Foundation (Kazak Türkleri Vakfi), previously mentioned, which serves a mainly cultural function. As a community and cultural center, its activities are oriented towards the promotion of Kazak culture. It maintains a public access library and has in the past held Kazak language classes for children, since many young Kazaks do not speak Kazak anymore although many understand it. It currently hosts Koran classes for children and also serves as a place for the preparation of communal meals for weddings and for the gathering of wedding guests.

The Foundation's importance as a focal point for cohesion building is significant. As the cultural center for the community the Foundation acts as a gathering place for 
community members and Turks alike who identify as friends of community members and the community itself. It is a cultural focal point for the community as major cultural events of community importance are conducted there. Kazak children have spent many an afternoon together at the Foundation in Kazak language classes. This inevitably influences identity building as members of the Kazak community in these child participants as exposure to cultural aspects of the community in a more formal setting are likely to reinforce and support a cultural identity. As such, it is part of the process of formalizing culture. Likewise, afternoon Koran classes for girls between the ages of 6 and 13 with classes numbering 20-25 girls during the summer is evidence of the cultural drawing power of the Foundation as well as that of an actively participating community. The concern with Islam as a function of Kazak identity appears multiple times in various forms in the Foundation's key activities (see Methodological Approach and Research Design section). Religion is seen as a part of the Kazak identity and the version of Islam practiced by the Kazaks is the same as practiced by the wider Turkish population it still plays a role important to cohesion as a Kazak community member.

Weddings are one of the most important events organized through the Foundation. They bring together hundreds of friends and relatives. The Foundation provides a space for the preparation of the traditional wedding meal - rice and mutton with carrots and currants. Guests gather in adjacent large rooms to sit together on the floor and share the meal together with men and women traditionally eating in separate rooms as would be traditional in the yurt, the domed wood framed and felt covered tent Kazaks and other pastoral nomadic groups used in a pastoral lifestyle. In the evening, the Foundation hosts the entertainment portion of the wedding where the young members of the community 
have a chance to meet, dance and drink tea together and enjoy themselves. These are important events for the coming together of those community members who may otherwise have little contact with one another and for a means of individual social exchange within the community.

The Foundation is also a place where meetings concerning community-affecting events are conducted. One such issue currently involves the building of a 2,000 residence development project by the government Housing Development Administration (TOKİ). Kazaks from the community mostly living in Istanbul, other areas of Turkey and abroad who wish to invest in a home in the project were invited to attend the meeting to discuss their options and opportunities for investment. Without the Foundation as a community resource, many would likely not be aware of the project and many such opportunities would likely be missed.

The Foundation functions as an internally linking agent to other members of the community as well as serving as an external link between the community and the greater Turkish society as well as the government of Kazakhstan as an intermediary. As discussed in the moral economy section, the Foundation serves as the link between job seekers and employers providing a very important source of social capital. The Foundation reported that job notices circulate through the Foundation. Firms or institutions looking for employers may contact the Foundation who then notifies the community The contact is then facilitated through the Foundation itself. Such offers may be small, such as a case related where a local hospital was in need of a janitor, but at times they involve international positions particularly in Kazakhstan or other business opportunities also in Kazakhstan (Interview with Abdülselam Makoç, 11/12/2011). Its 
ties to the government of Kazakhstan, through which it is able to channel funding for education, collaborate on cultural events, provide jobs and business opportunities for the Kazak community in Istanbul, and facilitate cultural exchanges for young Zeytinburnu Kazaks are ways in which it serves as a bridge between the community and the greater societies in which it is involved with.

The Position of Education in the Community and its Relationship to Social Capital

Putnam claims that "education is the most important predictor for many forms of social participation" (p. 418). This claim was echoed in Şirzat Doğru's statement, the Kazak cultural entrepreneur of Alaş Kumis Çiftliği (The Alaş Kumis (fermented mare's milk) Farm), about education and cultural continuation. He expressed the notion that education was a positive ingredient for the longevity of the community and the continuation of culturally specific practices. That education is not seen or experienced by key community actors as a culturally weakening or destructive force, however, is an important testimony to the possibility for these two sometimes oppositional elements to coexist and strengthen one another. Education is seen by some community members as a participation enhancing ingredient. Within this view is the notion that if people are educated then they can understand themselves better and thus have a better understanding of their own culture. This presumably provides individuals in the community with a more developed sense of the meaning of their culture and its significance in their lives.

A real obstacle to education for the community was the turbulent political environment of the 1970s and 80s a time of political breakdown where right and leftwing factions openly battled in the streets of Istanbul. These events reportedly stunted 
the formal educational development of the community. People were unable to regularly leave their homes and university attendance was sporadic or ceased entirely for fear of being attacked or caught in attacks in the street (Interview, Abdülselam Malkoç, 05/4/2011). Universities were sometimes dangerous places that were controlled by either right or left-wing groups and control could shift from one to the other. Community leaders admittedly neglected education as they worked in their manufacturing plants because their economy was sound and less need was felt for it (Interviews, Şirzat Doğru, 18-6-2011; Abdulvahap K1lıç, 24-6-2011). There is much regret among community elites for not emphasizing the importance of education more strongly. It is felt that had education been a greater priority, the community would be in a stronger economic position today.

At the time of Çiğdem's study, partner choices for community members were reflected in their expectations related to education levels. The data in the table below includes findings for education levels and partner choice in the Kazak community (Çiğdem, p. 123). As education levels increase the necessity for one's spouse to be of the same ethnic group and from the same origins decreases. On the other hand, the desire for one's spouse to be related in some way increased slightly with increased education but the numbers for each education group was very low for this category and perhaps not of great signifigance. Between a middle school education and a university education, the desire for one's spouse to be educated remained nearly the same while the importance of having a physically attractive spouse increases. The need to be with a spouse who is a good match also becomes more important with an increase in education. Expectations were assumed to increase with greater levels of education and hence the desire for more 
attractive and suitable spouses as well as more educated ones, however the difference of increase at the university level education is rather slight.

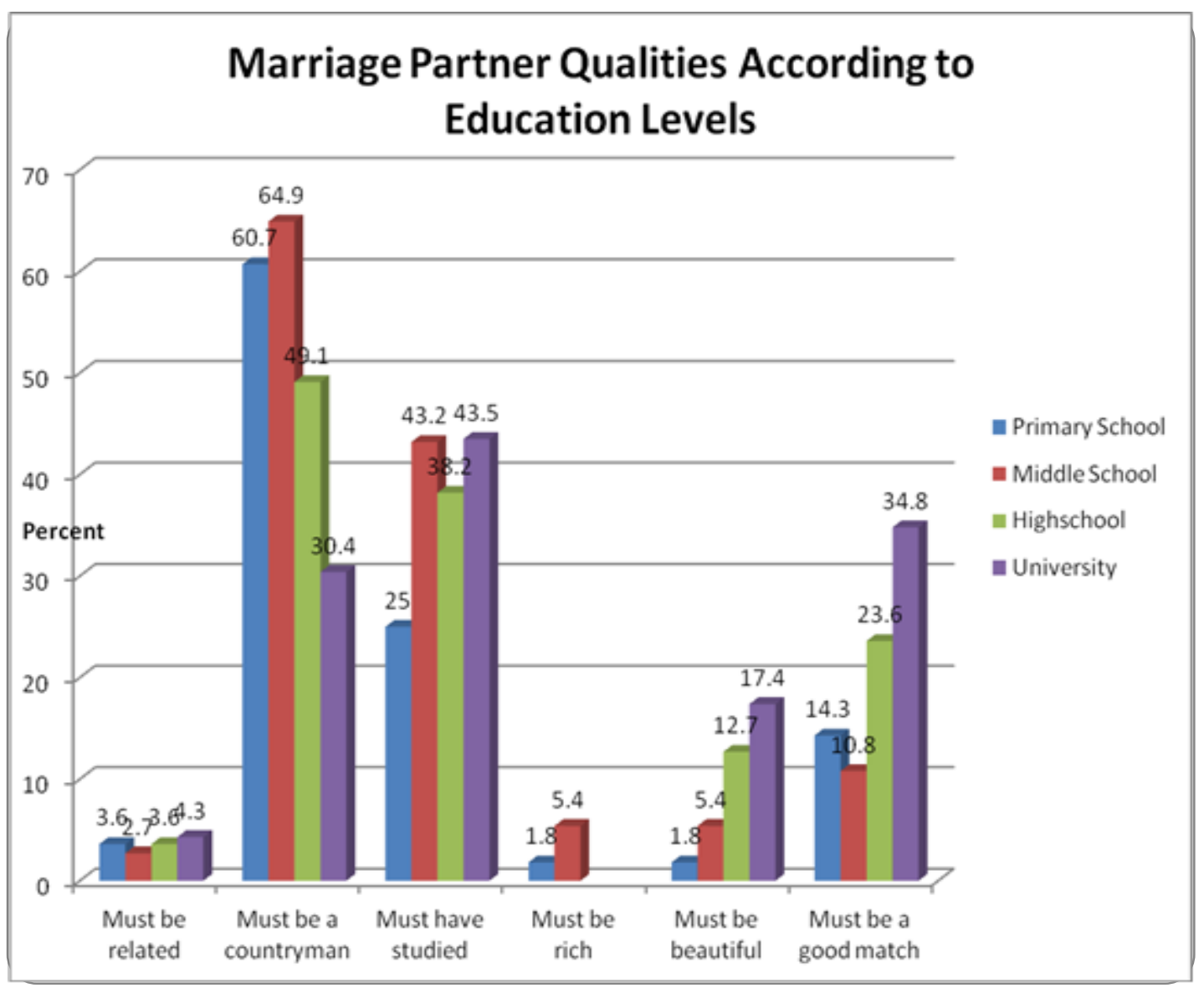

\section{Table 7: Marriage partner qualities according to education levels}

At higher levels of education, choosing a spouse that is well versed in the cultural practices of the community is apparently less of a priority than whether or not they are a good match. This fits in with the common findings of ethnic enclaves and outmigration with the increase of education levels. This does not necessarily indicate a decrease in cultural involvement as indicated by reports from interviews with community members, especially those for whom education was a key factor in perpetuating community and 
cultural values. It was reported that the relationships of many Kazaks who marry outside the community end up in divorce due to differences in culture that cannot be reconciled. The issue was treated by Abdülselam as a mild form of acceptance with often unfortunate irreconcilable consequences as an almost foregone conclusion and an indication that there is still enough cultural difference for individuals to prefer marriage within the community. But the opinion that marrying within the community is not necessary may be a reflection of the broader thinking that an education brings, however, in practice this may not play out this way. A significant implication for the education level expectations in educated community members is the potential for the creation of upwardly rising expectations in terms of this quality. In the long-term, this could have positive impacts for the Kazaks as a distinct, successful, well educated and professionalized minority group influenced by internal pressures to develop in this direction.

\section{Risks of Social Capital and Cohesion Breakdown}

Putnam provides several consequences for the breakdown of social capital and cohesion. These include greater difficulty in resolving social problems and a potential compounding of problems on the family level (p. 299), a reduction in civic engagement (p. 254), a potential lower school performance in children (p. 302), a decrease in tolerance with lower social participation (p. 355), decrease in income distribution equity (p. 359), potential ill health effects such as increased heart disease in those with fewer social ties (p. 329), and higher crime rates (p. 307) among other unpleasant possibilities. The weakening of the cultural practices of a community may aggravate these aspects and bring on serious levels of decline. 
The Foundation, in its way, provides some defense against the deterioration of social capital and cohesion for the community. Physically, it offers a space for community members who might otherwise have sparse contact with one another and potentially mitigates and in this way minimizes the potential breakdown of social capital and cohesion. The interactions observed in the course of this research were rich in connection building and community members took advantage of the opportunities of the services the Foundation provides.

\section{Missed Opportunities for Enhancing Social Capital}

In the 1970s, Kazak community members had opportunities to enter into local municipality offices. The qualifications for such offices were lax and positions were easy to obtain. Community elites, however, the majority of potential candidates did not take advantage of the opportunity being content with their economic situation at the time and chose to focus on their manufacturing operations (Interview with Abdülselam Malkoç, 15/8/2011). In the following decades, and as institutions developed, the requirements and qualifications for public office became more demanding and most of the Kazak community moved out of the running for public office. Simultaneously, the community's main industries took a turn for the worse and were subject to market invasion from local entrants and later from foreign imports. It was at this point that it was realized that holding a position in public office would have been advantageous if for no other reason than the assurance of a stable income for some community members. For other reasons, the network and ties to political structures of the community would have been greatly enhanced by such entrance into the local municipality. This is an opportunity lost that is reportedly regretted by some community members, particularly Foundation members and 
students who were not necessarily affiliated with the Foundation, who realize the value of what those positions could have brought on a personal as well as a community level.

\section{Current Political Ties}

Although not as strong as they could have been, the community does possess ties to political institutions. There are two Kazak community members that hold positions in the Zeytinburnu municipal government, İlyas Saka, an assistant to the Zeytinburnu mayor, and the Zeytinburnu Municipal Cultural Events Manager, a cultural event coordinator at the Zeytinburnu Municipality. Neither of these officials have direct contact with the community through their official activities, however, their positions do provide an important source of bridging social capital for the community to informally tap into. By virtue of their positions they are connected to and surrounded by people in a variety of sectors. They at times act as bridges from the community to these sectors. Although the networking activities they perform happen unofficially, they are able to link members of the community to employment opportunities when such opportunities arise.

Another linkage for the community, previously mentioned, is its relationship with the Republic of Kazakhstan. The activities coordinated with the government of Kazakhstan through the Greater Istanbul Municipality are cultural and business in nature. These activities began in 1991 when Kazakhstan became a sovereign state. The state began to build connections with the Kazaks living in Turkey, strengthening multilateral relations through the World Association of Kazakh People chaired by Kazakhstan President, Nursultan Nazarbayev (Rakhymbekov). An example of this is the October 24, 2009 visit of Nursultan Nazarbayev with Turkish President Abdullah Gül and Istanbul Mayor Kadir Topbaş at the Istanbul Congress Center. This event facilitated the meeting 
of 100 businessmen from Kazakhstan with 415 Turkish businessmen (İstanbul Büyükşehir Belediyesi, November 24, 2009). The community receives the benefits of bridging social capital from these international interactions through some work and business dealings with Kazakhstan as well as education gifts from the Kazakhstan government for students of Kazak origin living in Turkey.

\section{The Space Issue for Cultural Reproduction and Cohesion}

There are cultural activities in some communities that inevitably develop out of their subsistence practices. The Kazak community in the Altai region of western China required a vast amount of space for their nomadic livelihood. Moving from summer to winter pastures with yurts and livestock, the culture by which their community held together was one that developed with a close relationship to the open space in which they lived. As a consequence, many of their cultural practices and activities require a large amount of space. Urbanization has made the performance of many of these activities difficult if not impossible. Community members have expressed remorse over the inability to continue these practices some of which include being able to ride horses, playing the game of kokbar (described above), holding large gatherings in homes or on one's property, and being able to enjoy special meals and cultural foods that require an open space to prepare due to the cooking method which requires large open fires (Anonymous, Janitor, 10-7-2011; Interview, Female Store Owner, 5-4-2011).

The organization of space is not only an issue for the reproduction of these specific cultural acts but also for a more spontaneous fine tuning of social cohesion. When some of the community first began moving to Istanbul in the mid-1950s, they built 
their own houses in the empty spaces of the Zeytinburu area outside the old Byzantine defensive walls. Houses were typically one or two story detached homes with yards and were termed gecekondu, which means "built during the night" and refers to a kind of squatter arrangement in which an illegal dwelling built on public land cannot be destroyed and the inhabitants evicted if there is evidence that the building is being inhabited. This kind of detached housing permitted free-flows of exchanges and interactions between community members who could engage with one another across their yards. The opportunity for spontaneous interaction was relatively high. Shortly after this, the housing market exploded in Istanbul and now landless migrants from Anatolia began moving to major cities in the wake of agricultural industrialization in the 1950s. Land values increased and pressure to subdivide land for the building of cheap concrete apartment buildings grew. Under these circumstances, the Kazak community was pressured into following suit and sold their plots if they owned them or handed over their plots if they did not to developers in exchange for apartments in the new buildings. Respondents claim that this change in spatial organization of the neighborhood from detached homes with yards to apartments with no or little outside space and very little organic and spontaneous contact between dwellings had a significant impact on the ability of the community to interact spontaneously and to continue to reproduce certain cultural activities. Where neighbors could previously interact over a shared outside wall while performing household chores this kind of activity now became physically impossible from apartments (Interviews with Abdülselam Malkoç, Kazak Turk Foundation Manager, 12/11/2011 and Anonymous, Janitor, 10/7/2011). The reduction in possibilities for the reproduction of culture through the reduction of space is significant 
for its effects on social cohesion that is reproduced through cultural activities. One respondent said that "It's a space issue. There isn't space available to practice some of our cultural traditions" (Interview with Anonymous Janitor, 10-7-2011). This is a reminder of the importance of urban design in facilitating social relationships, a key factor being soft edges where semiprivate and public spaces meet and most social interactions occur in urban environments (Gehl, 2010).

Money was also indicated to be a key component in the reproduction of certain cultural practices. Large dinners, cultural events and funerals are such events that require money, or wealth in other resources such as the primary materials of the event, to reproduce. Things that were perhaps done as a matter of course and integrated into the normal operations of the community are now almost extra events that are valuated monetarily and can only be practiced when sufficient surplus funds are available. Whereas mutton was more readily available for celebrations in a pastoral environment through the result of directly applied labor, it is more costly in an urban environment in the hourly or daily wage required to purchase it. The act of having to purchase it makes it a step removed from cultural activities as it is no longer directly produced by the culture that consumes it.

\section{Vision for a Kazak Community}

The current economic situation has affected the desires of some community members in terms of the way they would like to see the community organized spatially as well as socially. For some, a kind of pastoral vision is what they have in mind for the community or at least a portion of the community. They would like to see and create a 
place where the community can to some degree continue the kind of lifestyle they had in the Altai Mountains in the Xinjiang province of northwestern China. This vision was described as "a village setting where the community could continue the practices specific to our culture where we could have the physical space and resources" for the means of production for those practices, products and social exchanges. In specific terms, some of these included the production and preparation of culturally specific foods, the continuation of a horse culture, and to some degree an economy based on animal rearing and its products (Interview with Abdulvahap Kılıç, 24-6-2011).

Şirzat's kumis farm is in many ways a recreation of this vision. The farm has horses for riding, produces a culturally specific drink, kumis, made from fermented mare's milk, offers traditional meals and invites visitors to visit a large yurt on the property built to look like a traditional yurt. He stated in interviews that he experienced losses in the business for the last several years and only this past year did he begin to experience profits. He claims to have launched the project with savings from his previous businesses and that he did not expect the business to really earn an income.

His stated reason for launching the business was to provide a beacon of culture for the community and to attempt to enable the culture to live on. It was envisioned as a rallying icon that could inspire the greater Kazak community in Turkey to devote greater importance to their cultural heritage. His economic activities are atypical of those of the economic rational actor. As such, he is likely to experience financial losses and may experience difficulty in maintaining his livelihood. The decision to attempt such a venture for the sake of cultural continuation defies assumptions on rational economic activity and gives credence to the claim that not all actors make choices that can be boiled 
down to what is most rational and self-benefitting. His activities have a social and cultural function that, at least in the intention, take primacy and extend beyond the scope of economic profit. This socially beneficial function is the giving of importance to the community's culture with the intended goal of strengthening internal relations through the symbols of an ethnic and community identity. These goals have no quantifiable economic benefit and do not translate into economic profitability but have enormous value in the community legacy they attempt to foster.

\section{Connectiveness as Obstacle for Advancement?}

Social capital, if too bonding, may serve to restrict the movement of community members and limit freedoms. This has apparently been the case at some points as reported by respondents. In the violence of the 1970 s and 80 s an unofficial big brother group emerged whose self-appointed task it was to "protect" the girls of the community. It was reported that this group also restricted the relationships girls could have with boys from outside the community restricting their freedoms and limiting their mobility in the name of community preservation.

The extent to which this kind of activity is an issue for the community was revealed in a long interview with a community member in the form of an anecdote. The story told was about three ethnic groups who are in three separate pits of hell.

"I'm going to tell you an anecdote. Imagine this. There is a pit and in it are three groups of people, Turkic peoples, Europeans and Jews and everyone is trying to get out. One of the Jews starts climbing the walls. The other Jews start pushing him up and as he gets going start cheering and cheering until he gets to the top and gets out. One of the Europeans then starts climbing. No one helps him but no one tries to stop him either. He gets close to the top but can't hold on and slides back down to try again later. Now, one of the Turkic people starts climbing. He works his 
way up the wall and just when he gets to the top the other Turks jump up and grab him and pull him back down. You see? This is our situation." (Interviews with a community member, 12-11-2011) ${ }^{3}$

The community member's comment was clearly indicative of a society where there may be a great deal of negative social controls are at work which serve to restrict its community members. He then cited real examples for this phenomenon one of which was in regard to a café opened by the Foundation as an income generator the funds of which would go towards the Foundation's cultural and educational activities. The café eventually had to be closed down due to the nonpayment of tabs by community members who felt it was their right to enjoy the services of the café without offering compensation. Szretzer says that "Generalized reciprocity is defined as widespread and transitive trust and trustworthiness among the members of a large social group" (Szretzer, p. 574). Without this relationship contributions from the community are not likely to emerge and larger projects that require community initiative will result in failure. The aksakal community leaders of the past were bestowed with decision making abilities respected by the community simplifying the task of community mobilization. Having no such notable leaders today, the task is a much more complicated affair.

Just how strong the downward pull in the community is difficult to determine. It may function to keep the community above a certain level of destitution while, at the same time, restricting the capacity of some community members to achieve prosperity. Those who have left the community may choose to maintain only weak ties with it in order to drastically limit their responsibilities and obligations to redistribute their wealth

\footnotetext{
${ }^{3}$ The identity of the community member was left anonymous to avoid potential undue negative attention from the community.
} 
to its struggling members. This works both ways in that as free as one is from

community bonds, one is also likely to experience lower levels of status within the community.

\section{The Younger Generation}

The youngest generation of high school and university students in the community exhibits signs of disinterest in traditional Kazak culture. Although young children are brought up in a clearly culturally specific environment in many cases, as they move into high school and university age many reportedly adopt more Turkish and western habits. These include, listening to western music such as rap, European music, and the ability to speak only Turkish, forgoing Kazak as an important language related to identity. These indicators coupled with the lack of Kazak language ability (common in other ethnic communities by the third and fourth generations) the lack of interest in the culture of their community and the lack of a culturally specific identity that is reported by several respondents, it appears to be a part of a group of significant indicators of a real change in the culture of the youngest generations. While young people in the community do not necessarily move out of their parents' homes after marriage or graduation from high school or university, they do not possess a necessarily strong tie to being Kazak.

The pressures of a very competitive economy is reflected in the university system and a tight labor market where unemployment is high at $18.6 \%$ in the 15 to 24 age bracket (Vela) and creates a great deal of pressure on youth. Stringent university entrance exams for qualifying into good schools and specific departments in those schools occupy a very large amount of students' time. Students may begin preparing years before they take the exams to ensure that they are on the track to establishing a 
solid future. A poor score likely means that a student will be unable to attend a top university thus severely hindering their chances on the job market where employers often choose young graduates from the best schools in order to increase the prestige of their companies (Vela). The pressure of this exam is likely the most important and time consuming factor in the lives of young people in Turkey who intend to study. It was indicated by the Zeytinburnu Municipal Cultural Events Manager, an administrator of Kazak origin at the Zeytinburnu Municipality Cultural and Social Projects Office that "young people from the community often do not have much time to come together or to engage in culturally related activities because of demands like the university entrance exam and other high school exams" (Interview with Zeytinburnu Municipal Cultural Events Manager, 25-11-2011). This suggests a widening rift between individuals among this segment of the community and a weakening in the maintenance of social cohesion and bonding social capital. The result may be that young graduates develop more external ties while those to their community weaken. Is this a case of community in crisis where the demands of a market economy seek more qualified workers and demands in time and personal investment increases as is expressed in its university exam? If it is, it is too early to tell what the next generation of the Kazak community will look like. Young graduates with strong community ties would serve to benefit the entire community. Young graduates disconnected from their community are less likely to pass on the benefits of their education to other community members and to be bridging agents between their community and the greater society.

In communities with declining levels of social capital cohesion, education may be a partial antidote in the continuation of a community's cohesion. Where forces that 
reduce the amount of individuals' free time, increase the competitive pressure on individuals and draws their focus continually outward and to a de-culturalizing level in the local sense and into a vague global identity in the greater sense, the ability of education to increase introspection and self-awareness for individuals to ask the questions that re-root them in a locality and a community, albeit with a newly transformed relationship to that community, may provide the vehicle that preserves community. This was the process that the Zeytinburnu Municipal Cultural Events Manager underwent when realizing that she was not quite Turkish. In high school, she said "she began to question her origins because of the differences in her appearance to her classmates" (Interview with Zeytinburnu Municipal Cultural Events Manager, 25-11-2011). After finishing high school, her father told her that now she can do something for her community. This was the first event that would begin a process of transformation in which she would pursue a degree in history and from there begin asking questions about her origins and work actively on cultural projects pertaining to her community. She believes, like some other community members, that rather than eroding community, education serves to strengthen the bonds of community through the creation of greater self-awareness and the process of inquiry. The seeds of this inquiry and self-awareness were planted during the process of interaction with other classmates and encouragement from her family, however, education became the means through which this new state of consciousness developed.

Since education articulates individuals to various economic opportunities, if that individual is anchored in a community, the result is likely to have a positively upward moving effect for the greater community. While a globalized economy pulls 
communities toward dissolution via its homogenizing culture and creates a sense of identity attached to global values of mobility, access to its bounty through high wages, cultural symbols and symbology that replace local ones, the functions of the global economy in its increasingly labor outsourcing and informalizing mechanisms and economic pressures through operations such as the increasing abstraction of property into investment tools, the results of which were witnessed in the 2008 economic crisis, the pressures placed on communities, which may respond by increased atomization, are enormous. In the case of migrants, the host country and its institutional and cultural demands are factors that may further act to pressurize and eventually dissolve the community. The Kazaks responded to these pressures as well as a result of a difficult and painful migration process by tightening up the community. The community still maintains a closed structure in many ways but it is clear that for the younger generation the hold is weakening but at the expense of cultural identity and while the negative aspects of membership to a conservative community are shed with weak participation so are the positive ones.

As the presence of social capital is essential as a "prerequisite for mobilization and reform" (Putnam, p. 399) the capacity of the community to activate around issues that affect it as a community depends on its stocks of social capital and cohesion. Without such links and connectivity individuals may experience a diminished level of local recourse. In a political environment like Turkey's where dissidence is met with firm resistance and minorities are viewed with suspicion as potential fifth columns, room for movement and mobilization is limited. The Kazaks have in the past been accused of being communists simply for having once resided in a country that later became 
communist and so have had to maintain a cautious approach to dealing with community wide issues. This may have been a contributing factor for the lost opportunity of viable community members to become involved in politics after leather and later plastic businesses began to struggle and/or fail. 


\section{Chapter VIII. Conclusions}

The initial cohesiveness of the Kazak community when it first arrived to Turkey in the 1950s was a fundamental asset. In comparison with other Central Asian groups who came as individuals or individual households but moved to the Zeytinburnu neighborhood in Istanbul to take advantage of an established cultural infrastructure and familial connections for economic reasons, the Kazaks are reportedly much better off economically. Their group advantage in terms of their ability to pool resources, to use established socio-political structures in firm organization, and to mobilize community members through a shared interest facilitated their initial economic successes. The existence of a kind of moral economy brought with them from their pastoralist homeland has made them more resilient to their new economic environment. Innovation of traditional societal structures transferred to the firm model and skills in leatherworking played an enormous role in the community's economic stability and growth.

The Zeytinburnu Kazak community-based economy, according to the testimony of some of the community's elites however, and observations through the course of this research, is currently a state of shambles and much more fragmented than anticipated at the start of this research. The perceptions of other Central Asian groups that the Kazaks are a wealthy community are relative to their own economic status which they perceive as more precarious. The expectation at the start of this research is that the Kazak community was thriving and commanded a strong community-based economy.

External blows from major economic shocks such as the importation of cheaper goods into the local market by competitors, the inability of the community or its main economic actors to follow trends in markets possibly exacerbated by the lack of 
importance placed on education and a complacency with successes achieved, and the shifting of resources to the production of goods that have a more generic quality less rooted in metis or local skills and relevance (plastics) and thus more easily and cheaply produced elsewhere, has severely negatively affected the community. The move to a wage labor system seems to have contributed to a lower level of community investment and stake in firm success on the one hand, however may have freed up the working class to seek other pursuits (although this is inconclusive but there is the possibility that labor relationships were exploitative and although these relationships maintained the social bonds that facilitate cohesion these may have been negative in nature). This followed the attempt of community entrepreneurs to distance themselves from the demands of the community or community shareholders to share greater portions of profits by going it alone and employ more flexible labor with less investment and fewer socially motivated financial demands on the community-based firms as exemplified by Şırzat of the Alaş Kumıs Farm. Entrepreneurs like Şırzat may have found that community shareholder demands made community based firms too costly from a management perspective and, as he testifies, may have put such firms in economic jeopardy from community shareholder demands for quick returns. In their new urban environment where obligations to community members had been weakened by major changes in the Kazak's formerly pastoral economy, such moves away from community based firms were more easily accomplished.

Kazak community entrepreneurs engaged in significant risk in launching their leather, and then plastics enterprises, the first mitigated somewhat by community sourced investments. The discontinuation of these enterprises due to market invasion by 
competitors in the leather sector as well as an inability to innovate and follow trends followed by the undercutting of the plastics industry by less expensive imports left them disadvantaged and unable to operate effectively. The precariousness of the global economy and its tendency to undercut local producers is a persistent threat to local actors and community-based economies. The very specific kinds of leather products produced by the Kazaks had a limited market and thus eventually lost their desirability when their primary "hippie trail" buyers no longer accessed the market. Although derived from a very particular skill set, these products were not universal enough to maintain a continued interest to a wide enough market had they maximized this skill set to produce a diversified range of goods to appeal to a broader set of buyers. The subsequent production in plastic goods such as flooring and sheeting, a decision made because demand had decreased for Kazak leather goods and attractive opportunities emerged in plastics, had a universal enough demand but not culturally or otherwise specific in any way and thus vulnerable to less expensive products from abroad. The community economy of the Kazaks was vulnerable because of the limited and relatively short-term demand of its goods and later vulnerability to cheaper products. In addition, the economy was harmed from within by actors who engaged in dishonest sales practices selling goods at inflated prices. These factors and events exposed the serious shortcomings of the community's economic base. The inability of the community to adjust to external changes in market demand and to adapt accordingly through adaptations such as specialization through education have been critical to its economic health.

The return to cultural enterprises that promote the unique traditional qualities of the community for some actors like Şirzat Doğru and the Alaş Kumis Farm reflects a 
retraction to the known and safe arenas in which only they possess expertise, in effect, an economic niche. Through such endeavors, competition is eliminated and such businesses serve the purpose of cultural promotion and the carrying on of cultural traditions which may fill the vacuum left by the weakening of vital social cohesion exacerbated by dissolution of community based firms.

The direction of the community today is uncertain. It is no longer the case that social relationships form the basis of its economy. As noted by several community members, the lack of investment in education was a crucial factor for the decline of the community's economic situation as was the missed opportunity to enter into local politics that became impossible later without a certain level of education. Many are encouraging the current generation to more rigorously seek education as a means towards some measure of economic recovery. Education is viewed by some community members as the link between economic prosperity and the preservation of Kazak culture in Istanbul and greater Turkey and cohesion in part for the social capital it can provide. The danger is, however, that education may create stronger links to non-community elements than to community-based ones, thus increasing bridging relationships but reducing bonding ones.

Outreach towards the nation of Kazakistan for business and cultural linkages is another strategy that the Foundation is using to strengthen community cohesion through the employment of social capital and fits with Betts's claims that refugee populations often bring with them or create international linkages. This has created some interest in Kazak language learning as well as creating some education and business opportunities to help bolster the community's prospects but according to the Zeytinburnu Municipal Cultural Events Manager “the Kazakhstan connection really doesn’t offer much incentive 
to learning Kazak. The Foundation lacks professionalism and so doesn't effectively reach out to community members to encourage language class attendance" (Interview with Zeytinburnu Municipal Cultural Events Manager, 25-11-2011).

As community leaders struggle to compensate for mistakes and missed opportunities along the road to the present, the prosperity enjoyed by the community that fed into the connectivity between its members will likely never again be experienced to the same degree. The loop that circulated from economy to community and back is likely irreparable and the community and its members must find new ways to move forward. In short, the Kazak community in this study is an example of an innovating refugee community plagued in some ways by their own success and extension into risky endeavors, limitations on their continued ability to maximize their unique advantages coupled with a blow from a changing economic regime, further compounded by a distancing of capital and firms from the community base which may have greatly reduced their resilience and, in turn, that of the community.

In essence, the Kazak leather economy was shaken by several internal as well as external shocks. A movement within the community currently exists, represented by the Foundation and cultural economic actors such as Şirzat, to maintain social cohesion through symbols and reproduction of cultural identity. This researcher feels that that this and other similar attempts to maintain cohesion may be an attempt to replace the loss of cohesion that was previously embedded in the social relations that once drove the Kazak economy as a community effort. One elite community member also brought up a point that bears further reflection. Are there cultural forces within the community that create a downward pull for those who achieve success as illustrated by the anecdote about the 
three ethnic groups in the pit that incentivize successful members to distance themselves from the community? This is certainly not unique to the Kazaks. But whether the main issue is a breakdown in social cohesion through a process of urbanization that resulted in economic vulnerability, or a series of economic shocks that shook the foundations of the community's mechanisms of social cohesion, this research was unable to fully determine. It was, however, able to determine that an economy for community was not successful in the Kazak case, despite its advantages of initially strong cohesion through shared identity and experience of hardship and a niche skill set which it was able to exploit through clever positioning in the Turkish market, and to identify some of the factors that led to its failure. In uncovering this, it has revealed more questions and perhaps the need for a further inquiry. Along these lines, the role of religion in maintaining cohesion in the community and the role it plays in the construction of the new Islamic political narrative of Turkey, for example, deserves a closer look but is for an entirely different study. How youth in particular respond to the Foundation and its outreach activities also deserves more consideration as well as how they articulate themselves socially and economically. And there are others.

What this case means for other refugee communities may have some importance. Early identification of the shortcomings of the Kazak economy could have drastically altered its direction making economic actors more responsive to market demands and diversifying its products to ensure that drop in demand for any one product line would not upset the entire system. This may be useful for informing livelihood projects or policies aimed at supporting refugee or other migrant communities. Subsequently, a balance between economic articulation and the maintenance of the unique qualities of a 
community which preserve its diversity make for a more vivid urban landscape and are both goals that require sensitive consideration. There must be more incentives to continue to participate in community reproduction than disincentives. When these bonds gain momentum through economic expressions they become more durable and sustainable and people in communities continue to prosper together. 


\section{Bibliography}

Aldrich, H. E., \& Waldinger, R. (1990). Ethnicity and Entrepreneurship. Annual Review of Sociology. 16, 111-135.

Arrighi, Giovanni (2000). The Long Twentieth Century: Money, Power, and the Origins of Our Times. Verso, London.

Arrighi, G., Silver, B. J., \& Brewer, B. D. (2003). Industrial Convergence, Globalization, and the Persistence of the North-South Divide. Studies in Comparative International Development, 38(1), 3-31.

Bauer, T., Epstein, G. S., Gang, \& Ira, N. (2005). Enclaves, Language, and the Location Choice of Migrants. Journal of Population Economics. 18(4), 649-662.

Benson, L., \& Svanberg, I. (1980). China's Last Nomads: The History and Culture of China's Kazaks. Armonk, N.Y.: M.E. Sharpe.

Berg, B. L. (2001). Qualitative Research Methods for the Social Sciences. Allyn and Bacon.

Betts, A., Bloom, L., Kaplan, J., Omata, N. (2014). Refugee Economics, Rethinking Popular Assumptions. The Humanitarian Innovation Project, University of Oxford.

Boratav, K. (1989). İktisat ve Siyaset Üzerine Aykırı Yazılar. BDS.

Boratav, K. (2003). Türkiye İktisat Tarihi 1908-2002. İmge Kitabevi.

Bourdieu, P. (1985). The Social Space and the Genesis of Groups. Theory and Society, 14(6) 723-744.

Berggren, E., Lilic-Brboric, B., Toksöz, G., \& Trimikliniotis, N. (2007). Irregular Migration, formal Labour and Community: A Challenge for Europe. Shaker Publishing.

Brisson, D. S., \& Usher, C. L. (2005). Bonding Social Capital in Low-Income Neighborhoods. Family Relations. 54, 644-653.

Chan, J., To, Ho-P., \& Chan, E. (2006). Reconsidering Social Cohesion: Developing a Definition and Analytical Framework for Empirical Research. Social Indicators Research. 75(2). 273-302.

Crenson, M. A. (1978). Social Networks and Political Processes in Urban 
Neighborhoods. American Journal of Political Science, 22(3), 578-594.

Clark, K., \& Drinkwater, S. (2002). Enclaves, Neighbourhood Effects and Employment Outcomes: Ethnic Minorities in England and Wales. Journal of Population Economics. 15(1), Special Issue on Marginal Labor Markets, 5-29.

Cobas, J. A. (1987). Ethnic Enclaves and Middleman Minorities: Alternative Strategies of Immigrant Adaptation? Sociological Perspectives. 30(2), 143-161.

Crawford, \& M. J.L. (June 7, 2011) "Turkish university exams get low good grade from foreign students." Hürriyet Daily News.

http://www.hurriyetdailynews.com/n.php?n=foreign-students-eye-turkishuniversity-exams-2011-06-07.

Çiğdem, Erdem (2002). Zeytinburnudaki Kazakların Socio-Ekonomi Durumu. Master's Thesis, Sociology Department of Istanbul University, Istanbul.

Daly, H. E., \& Cobb Jr., J. B. (1989). For the Common Good: Redirecting the Economy Toward Community, the Environment and a Sustainable Future. Beacon Press, Boston Massachusetts.

Dustmann, C., \& Preston, I. (2001). Attitudes to Ethnic Minorities, Ethnic Context and Location Decisions. The Economic Journal. 111(470), 353-373.

Edin, Per-A., Fredriksson, P., \& Åslund, O. (2003). Ethnic Enclaves and the Economic Success of Immigrants: Evidence from a Natural Experiment. The Quarterly Journal of Economics. 118(1), 329-357.

Erman, T. (1998). Becoming 'Urban' or Remaining 'Rural': The Views of Turkish Ruralto-Urban Migrants on the 'Integration' Question. International Journal of Middle East Studies. 30(4), 541-561.

Eraydin, A. (2008). The Impact of Globalisation on Different Social Groups: Competitiveness, Social Cohesion and Spatial Segregation in Istanbul. Urban Studies. 45(8), 1663-1691.

Evans, G. (1986) From Moral Economy to Remembered Village: the Sociology of James C. Scott. Working Paper No. 40. Centre of Southeast Asian Studies, Monash University Clayton, Victoria September.

Evren, B. (2003). Surların Öte Yanı Zeytinburnu. Zeytinburnu Belediyesi Kültür Yayınları.

Forced Migration Review. Innovation and Refugees. Refugee Studies Center. Supplement September, 2014. 
Forrest, R. \& Kearns, A. (2001). Social Cohesion, Social Capital and the Neighbourhood. Urban Studies. 38(12), 2125-2143.

Franz, E. (1994). Population Policy in Turkey. Family Planning and Migration between 1960 and 1992. Hamburg: Deutsches Orient-Insitut.

Fukuyama, F. (1991). Liberal Democracy as a Global Phenomenon. Political Science and Politics, 24(4), 659-664.

Fukuyama, F. (1995). Social Capital and the Global Economy. Foreign Affairs, 74(5), 89103.

Fukuyama, F. (2001). Social Capital, Civil Society and Development.” Third World Quarterly, 22(1), 7-20.

Gehl, Jan (2010). Cities for People. Washington: Island Press.

Gouldner, A. W. (1960). The Norm of Reciprocity: A Preliminary Statement. American Sociological Review. 25, 161-178.

Granovetter, M. (2005). The Impact of Social Structure on Economic Outcomes. The Journal of Economic Perspectives. 19(1), 33-50.

Granovetter, M. (2005). Economic Action and Social Structure: The Problem of Embeddedness. American Journal of Sociology, 91(3), 481-510.

Granovetter, M. (1983). The Strength of Weak Ties: A Network Theory Revisited. Sociological Theory. 1, 201-233.

Greenhouse gases rise by record amount. (2011, November 4). The Guardian. http://www.guardian.co.uk/environment/2011/nov/04/greenhouse-gases-riserecord-levels.

Hale, W. (1981). The Political and Economic Development of Modern Turkey. Croom Helm.

Huntington, S. (1971). The Change to Change: Modernization, Development, and Politics. Comparative Politics, 3(3), 283-322.

İkinci, S. (2005, May 30). Turkey: IMF plan demands new attacks on working people. World Socialist Website. http://www.wsws.org/articles/2005/may2005/turkm30.shtml.

Kazak Kültürü İstanbullularla Buluştu. (2009, October 23) İstanbul Büyükşehir Belediyesi. Retrieved April 10, 2011. http://www.ibb.gov.tr/trTR/Pages/Haber.aspx?NewsID=17764. 
Kazak Turk Foundation, May 17, 2011.

http://www.kazakturklerivakfi.org/index.php?option=com_content\&view=article $\underline{\text { \&id }=25 \& \text { Itemid }=28}$

Janjuha-Jivraj, S. (2003). Sustainability of Social Capital within Ethnic Networks". Journal of Business Ethics. 47(1), Small Business and Empirical Perspectives in Business Ethics, 31-43.

Kamrava, M. (2004). The Semi-Formal Sector and the Turkish Political Economy. British Journal of Middle Eastern Studies, 31(1), 63-87.

Kearney, M. (1996) Reconceptualizeing the Peasantry: Anthropology in Global Perspective. West View Press, Inc.

Keyder, Ç. (1987). State and Class in Turkey: A Study in Capitalist Development. Verso.

Knack, S., \& Keefer, P. (1997). Does Social Capital Have an Economic Payoff? A CrossCountry Investigation. The Quarterly Journal of Economics, 112(4), 1251-1288.

Kobrin, F. E., \& Speare Jr., A., (1983). Out-Migration and Ethnic Communities. International Migration Review. 17(3), 425-444.

Krippner, G. R. (2001). The Elusive Market: Embeddedness and the Paradigm of Economic Sociology. Theory and Society. 30, 775-810.

Krippner, G. R., \& Alvarez, A. S. (2007). Embeddedness and the Intellectual Projects of Economic Sociology. Annual Review of Sociology. 33, 219-40.

Lerner, David. (1958). The Passing of Traditional Society. Free Press.

Logan, J. R., Alba, R. D., \& Stults B. J. (2003). Enclaves and Entrepreneurs: Assessing the Payoff for Immigrants and Minorities. International Migration Review. 37(2), 344-388.

Logan, J. R., Zhang, W., \& Alba, R. D. (2002). Immigrant Enclaves and Ethnic Communities in New York and Los Angeles Author. American Sociological Review. 67(2), 299-322.

Massey, D. S. (1988). Economic Development and International Migration in Comparative Perspective. Population and Development Review. 14(3), 383-413.

Massey, D. S. (1999). International Migration at the Dawn of the Twenty-First Century: The Role of the State. Population and Development Review. 25(2), 303-322.

Massey, D. S., (2006). Magaly Sanchez R., Jere R. Behrman. Of Myths and Markets. 
Annals of the American Academy of Political and Social Science. 606, Chronicle of a Myth Foretold: The Washington Consensus in Latin America, 8-31.

Mütevellioğlu, N., Sönmez, S. (Eds.) (2009). Küreselleşme, Kriz ve Türkiye Neoliberal Dönüşüm. İstanbul Bilgi Üniversitesi.

Navarro, V. (2004). Commentary: Is capital the solution or the problem? International Journal of Epidemiology. 33, 672-674.

Özgün Ekonomi ve Makale Arşivi. Retrieved 2011, May, 18. http://www.ekodialog.com/istatistik/ozel_stat/as_ucret.html.

Education at a Glance: OECD Indicators. (2010). OECD.

Plastics Supply News: China's Imports Down on 2010; Turkey's Set Record. (2011, May 5). Plastics Today. Retrieved 2011, August, 10. http://www.plasticstoday.com/articles/plastics-supply-news-china-turkey-imports$\underline{05062011 .}$.

Polanyi, K. (1963), Ports of Trade in Early Societies. The Journal of Economic History, 23(1), 30-45.

Polanyi, K. (2001). The Great Transformation: The Political and Economic Origins of Our Time. Beacon Press, Boston, Massachusetts,.

Portes, A. (1998). Social Capital: Its Origins and Applications in Modern Sociology. Annual Review of Sociology. 24, 1-24.

Portes, A. (2000). The Two Meanings of Social Capital. Sociological Forum. 15(1), 1-12.

Portes, A., \& Stepick, A. (1985). Unwelcome Immigrants: The Labor Market Experiences of 1980 (Mariel) Cuban and Haitian Refugees in South Florida”. American Sociological Review. 50(4), 493-514.

Portes, A., \& Jensen, L. (1987). What's an Ethnic Enclave? The Case for Conceptual Clarity. American Sociological Review. 52, 768-71.

Putnam, R. (2000). Bowling Alone: The Collapse and Revival of American Community. Simon and Schuster, New York, NY.

Rakhymbekov, Arnur. (2009, November 26). Kazakh Diaspora in Turkey Ready to Become a Bridge in Friendship of Two Fraternal Nations. KAZINFORM. Retrieved 2011, May 13. http://www.inform.kz/eng/article/2207485.

Reardon, S. F. \& Bischoff K. (2011, November) Growth in the Residential Segregation of Families by Income, 1970-2009. Retrieved 2011, September, 28. Stanford 
University.

http://graphics8.nytimes.com/packages/pdf/national/RussellSageIncomeSegregati onreport.pdf..

Rostow, W. W. (1960). The Stages of Economic Growth: A Non-Communist Manifesto. Cambridge University Press.

Rothbart, Ron. (1993). The Ethnic Saloon as a Form of Immigrant Enterprise". International Migration Review, 27( 2), 332-358.

Sanders, J. M., \& Nee, V. (1978). Limits of Ethnic Solidarity in the Enclave Economy. American Sociological Review. 52(6), 745-773.

Sampson, R. J. (2008). What Community Supplies. Ed. James DeFilippis \& Susan Saegert The Community Development Reader. New York: Routledge.

Sayer, A. (1992). Method in Social Science: A Realist Approach. London, Routledge.

Sayer, A. (2000). Moral Economy and Political Economy. Studies in Political Economy 61 , Spring.

Secor, A. (2004). 'There Is an Istanbul That Belongs to Me': Citizenship, Space, and Identity in the City. Annals of the Association of American Geographers. 94(2), 352-368.

Secor, A. J., \& O'Loughlin, J. (2005). Social and political trust in Istanbul and Moscow: a comparative analysis of individual and neighbourhood effects. Royal Geographical Society (with The Institute of British Geographers), 66-82.

Scott, J. C. (1998). Seeing Like a State: How Certain Schemes to Improve the Human Condition Have Failed. Yale University Press: New Haven and London.

Scott, J. C. (1976). The Moral Economy of the Peasant: Rebellion and Subsistence in South East Asia. Yale University.

Smith, B. C. (2003). Understanding Third World Politics: Theories of Political Change and Development. Indiana University Press.

So, A. Y. (1990). Social Change and Development: Modernization, Dependency and World System Theories. London: Sage.

Szreter, S. (2002). The State of Social Capital: Bringing Back in Power, Politics, and History." Theory and Society. 31(5), 573-621.

Svanberg, I. (1998). Kazak Refugees in Turkey: A Study of Cultural Persistence and 
Social Change. Uppsala.

Swaroop, S., \& Morenoff, J. D. (2006). Building Community: The Neighborhood Context of Social Organization. Social Forces. 84(3), 1665-1695.

Türk-Kazak İş Forumu'na katılan Nazarbayev İstanbul'dan uğurlandı. (2009, October 24) İstanbul Büyükşehir Belediyesi. Retrieved April 10, 2011. http://www.ibb.gov.tr/tr-TR/Pages/Haber.aspx?NewsID=17768.

Ülker, E. (2008). Assimilation, Security and Geographical Nationalization in Interwar Turkey: The Settlement Law of 1934. European Journal of Turkish Studies. 7.

Vela, J. (2011, November, 16) The New Young Turks: Over-Educated, Tech-Savvy, and Jobless." The Atlantic. Retrieved 2011, November, 16. http://www.theatlantic.com/international/archive/2011/11/the-new-young-turksover-educated-tech-savvy-and-jobless/248535/.

Yin, R. K. (2003). Case Study Research and Theory Building. Sage Publications.

Yücel, Ç. (2002). Zeytinburnu'nda Yaşayan Kazak Türkleri'nin Sosyo-Ekonomik Durumu. Master's Thesis, Istanbul University. Retrieved from the Kazak Turk Foundation. 


\section{Interviews}

Interviews with Wakhan Afghan Kyrgyz community in Ulupamir, Erciş, Van Province Eastern Turkey, 2006.

Abdulvahap Kılıç, Kazak Turk Foundation Chairman, 24-6-2011

Abdulvahap Kılıç, Kazak Turk Foundation Chairman, 21-5-2011

Abdülselam Malkoç, Kazak Turk Foundation Manager, 5-4-2011

Abdülselam Malkoç, Kazak Turk Foundation Manager, 15-8-2011

Abdülselam Malkoç, Kazak Turk Foundation Manager, 12-11-2011

Interviews with a community member, 12-11-2011

Anonymous, Janitor, 10-7-2011

Anonymous, Plastic factory owner, 21-5-2011

Anonymous, Female Store owner, 5-4-2011

Female Student from Altai, China, 6-3-2011

Male Student from Altai, China, 16-3-2011

Zeytinburnu Municipal Cultural Events Manager, 25-11-2011

Şirzat Doğru, Alaş Kumis Farm owner, 18-6-2011 